\title{
tBid interaction with cardiolipin primarily orchestrates mitochondrial dysfunctions and subsequently activates Bax and Bak
}

\author{
F Gonzalvez ${ }^{1,9}$, F Pariselli ${ }^{1,9}$, P Dupaigne ${ }^{2}$, I Budihardjo ${ }^{3}$, \\ M Lutter $^{3}$, B Antonsson ${ }^{4}$, P Diolez $^{5}$, S Manon ${ }^{6}$, J-C Martinou ${ }^{7}$, \\ $M$ Goubern ${ }^{8}$, X Wang ${ }^{3}$, S Bernard ${ }^{2}$ and PX Petit ${ }^{\star, 1}$ \\ 1 Département de Génétique, Développement et Pathologies Moléculaires, \\ Institut Cochin, INSERM U567/CNRS UMR 8104, 24, rue du Faubourg \\ Saint-Jacques, 750014 Paris, France \\ 2 Objets Complexes et Interfaces d'Intérêt Biologique, CNRS FRE 2303, \\ Université René Descartes, 45 rue des Saint-Pères, 75270 Paris Cedex 06, \\ France \\ 3 Howard Hughes Medical Institute \& Department of Biochemistry, University of \\ Texas Southwestern Medical Center at Dallas, TX 75235, USA \\ 4 Department of Protein Biochemistry, Serono Pharmaceutical Research \\ Institute, Ares-Serono International S.A., CH-1228 Plan-Les-Ouates, \\ CH-1228, Geneva, Switzerland \\ ${ }^{5}$ Résonnance Magnétique des Systèmes Biologiques, CNRS/Université Victor \\ Segalen, Bordeaux 2, F33076 Bordeaux Cedex, France \\ 6 UMR5095 C.N.R.S./Université de Bordeaux 2, 1 rue Camille Saint-Saens, \\ F-33077 Bordeaux Cedex, France \\ 7 Cell Biology Department, University Sciences III, CH-1228 Geneva, \\ Switzerland \\ ${ }^{8}$ Laboratoire de Nutrition et Sécurité Alimentaire, INRA, domaine de Vilvert, \\ 78352 Jouy en Josas Cedex, France \\ 9 These authors have equally contributed to this work \\ * Corresponding author: PX Petit, Département Génétique, Développement et \\ Physiologie Moléculaire, Institut Cochin, INSERM U567/CNRS UMR 8104, 24 \\ rue du Faubourg Saint-Jacques, 75014 Paris, France. Tel: + 33144412411 \\ Fax: + 331444124 21; E-mail: pxpetit@cochin.inserm.fr.
}

Received 05.3.04; revised 11.11.04; accepted 29.11.04; publshed online 08.4.05 Edited by G Melino

\section{Abstract}

TNFR1/Fas engagement results in the cleavage of cytosolic Bid to truncated Bid (tBid), which translocates to mitochondria. We demonstrate that recombinant tBid induces in vitro immediate destabilization of the mitochondrial bioenergetic homeostasis. These alterations result in mild uncoupling of mitochondrial state-4 respiration, associated with an inhibition the adenosine diphosphate (ADP)-stimulated respiration and phosphorylation rate. tBid disruption of mitochondrial homeostasis was inhibited in mitochondria overexpressing $\mathrm{Bcl}-2$ and $\mathrm{Bcl}-\mathrm{XL}$. The inhibition of state-3 respiration is mediated by the reorganization of cardiolipin within the mitochondrial membranes, which indirectly affects the activity of the ADP/ATP translocator. Cardiolipin-deficient yeast mitochondria did not exhibit any respiratory inhibition by tBid, proving the absolute requirement for cardiolipin for tBid binding and activity. In contrast, the wild-type yeast mitochondria underwent a similar inhibition of ADP-stimulated respiration associated with reduced ATP synthesis. These events suggest that mitochondrial lipids rather than proteins are the key determinants of tBid-induced destabilization of mitochondrial bioenergetics.

\author{
Cell Death and Differentiation (2005) 12, 614-626. \\ doi:10.1038/sj.cdd.4401571 \\ Published online 8 April 2005
}

Keywords: apoptosis; Bid; bioenergetics; cardiolipin; mitochondria

\begin{abstract}
Abbreviations: ADP, adenosine diphosphate; ANT, adenine nucleotide translocator; AP5A, $\mathrm{P}_{1}, \mathrm{P}_{5}$-di(adenosine- $5^{\prime}$ )pentaphoentaphosphate; ATP, adenosine triphosphate; $\mathrm{BA}$, Bongkrekic acid; $\mathrm{BH}, \mathrm{Bcl}-2$ homology domain; $\mathrm{Bid}, \mathrm{BH} 3$ interacting domain death agonist; BSA, bovine serum albumin; CCCP, carbonyl cyanide-m-chloro-phenyl hydrazone; CsA, cyclosporine A; PTP, mitochondrial permeability transition pore; $\mathrm{CR}$, respiratory control ratio; tBid, truncated Bid (c-ter); TPP ${ }^{+}$, tetraphenyl phosphonium; $\Delta \Psi_{\mathrm{m}}$, mitochondrial membrane potential
\end{abstract}

\section{Introduction}

During the past decade, it has become unequivocally clear that most proapoptotic stimuli require a mitochondrialdependent step, involving disruption of mitochondrial bioenergetics ${ }^{1,2}$ (and for reviews, see Kroemer et al.., ${ }^{3}$ Wang $^{4}$ and Newmeyer et al. ${ }^{5}$ ) and outer membrane permeabilization. ${ }^{6-8}$ Proapoptotic proteins of the $\mathrm{Bcl}-2$ family regulate the pathways of apoptosis that induce the release of apoptogenic factors from the mitochondrial intermembrane space ${ }^{9}$ such as cytochrome $c$. Cytochrome $c$ is normally involved in the electron transfer from the bc1 complex (complex III) to cytochrome oxidase (complex IV). Once released into the cytosol, cytochrome $c$ activates the caspase cascade by inducing the oligomerization of a cytochrome $c$ dATP/Apaf-1/ pro-caspase-9 complex named apoptosome.

Moreover, it was recently reported that changes of mitochondrial physiology appeared during many apoptotic pathways $^{10}$ and could be induced by many pro- and antiapoptotic factors. Although the ability of $\mathrm{Bcl}-\mathrm{XI}$ and $\mathrm{Bcl}-2$ to affect mitochondrial energy metabolism has already been described, ${ }^{11,12}$ the mechanisms whereby mitochondrial physiology changes control apoptosis remains to be defined.

Bid is a widespread proapoptotic factor that belongs to a subset of the Bcl-2 family, and possesses sequence homology only within the conserved $\mathrm{BH} 3$ domain. ${ }^{13}$ Bid has attracted increasing interest since it was identified as a substrate of caspase 8 , following the activation of death receptors such as Fas. During apoptosis, cleavage near its $\mathrm{N}$-terminus by caspase- $8^{14,15}$ produces $\mathrm{p} 15 \mathrm{tBid}$, the active form of Bid, which can rapidly translocate to mitochondria and trigger cytochrome $c$ release. ${ }^{16}$ Truncated Bid (tBid) is 10 -fold more affine for $\mathrm{Bcl}-\mathrm{XL}$ than full-length $\mathrm{Bid}$ and is also 100 times more effective in releasing cytochrome $c$ from mitochondria. ${ }^{14}$ 
It was also reported that tBid interacts with mitochondrial contact sites by a specific interaction with cardiolipins ${ }^{17,18}$ and is able to induce remodelling of the mitochondrial membranes. ${ }^{19,20}$ The recent observation that tBid stimulates unravelling of the mitochondrial cristae and enhances the mobilization of cytochrome $c^{19}$ indicates that the early events affecting mitochondrial structure and function are linked to the insertion of tBid into the mitochondrial membrane. ${ }^{19}$ Despite the increasing knowledge on the mechanisms of tBid interaction with mitochondria, the consequences of this interaction on mitochondrial bioenergetic properties have not been elucidated.

The present study analyzes the consequences of tBid interaction with mitochondrial contact sites, and the mechanism by which tBid alters the bioenergetic properties of mitochondria. Using mitochondria isolated from wild-type cells, we demonstrated for the first time that tBid acts independently of Bak and Bax to slightly increase state-4 respiration as a result of uncoupling. Moreover, tBid inhibited ADP-stimulated respiration. Both these effects do not require the $\mathrm{BH} 3$ domain of tBid in the first place. We also report that $\mathrm{Bcl}-2$ and $\mathrm{Bcl}-\mathrm{XL}$ protect mitochondria from these changes via direct interaction between their hydrophobic pocket and the $\mathrm{BH} 3$ domain of $\mathrm{tBid}$. We therefore showed that tBid inhibits ADP-stimulated respiration by indirect inhibition of the activity of the adenine nucleotide translocator (ANT), mediated by cardiolipin reorganization into the mitochondrial inner membrane.

We also proved in this paper that the absence of cardiolipin (and consequently cardiolipin derivatives) in a cardiolipinsynthase-deficient yeast consistant with our observations, abolished subsequent effects of tBid. These results are based on biophysical approaches, showing that cardiolipins are required for $\mathrm{tBid}$ interaction with synthetic lipid monolayers. We finally showed that tBid triggered cytochrome $c$ release from the mitochondrial intermembrane space in part by transient mitochondrial permeability transition pore (PTP) opening and also by a mitochondrial membrane permeabilization insensitive to cyclosporine A (CSA). This mitochondrial membrane permeabilization is probably due to membrane rigidification linked to $\mathrm{tBid} / \mathrm{cardiolipin}$ relationship primarily at the contact sites with a subsequent action onto cardiolipin reorganization throughout the whole inner mitochondrial membrane.

These findings demonstrate that tBid plays a primary role in the mitochondria-mediated apoptosis pathway by disturbing mitochondrial bioenergetics. This may be a key event in predisposing mitochondria to the synergistic effect of tBid with Bax and Bak.

\section{Results}

\section{Mitochondrial bioenergetics: basic properties}

Throughout this work, we used Percoll-purified liver mitochondria from C57/BI6 wild-type (WT) mice, transgenic mice that overexpress $\mathrm{Bcl}-2^{30}$ or $\mathrm{Bcl}-\mathrm{XL},{ }^{31}$ and $\mathrm{BAX}^{-1-}$ and $\mathrm{BAK}^{-1-}$ mice. First, we investigated the basic bioenergetic properties of these mitochondria by monitoring succinate-oxidizing mitochondria. In particular, the oxidation rate ( $\left.V_{\text {oxidation }}\right)$, respiratory control (RC), ADP/O ratio, mitochondrial membrane potential $\left(\Delta \Psi_{\mathrm{m}}\right)$, and phosphorylation rate $\left(V_{\text {phos. }}\right)$ were analyzed as well as the basic conditions for PTP opening (in terms of large amplitude swelling' (Figure 1). Each parameter was obtained from the simultaneous measurement of oxygen consumption, $\mathrm{TPP}^{+}$concentration and $\mathrm{pH}$. A typical trace control (control mitochondria) is represented in Figure 2a. Figure 1a shows all steps of oxidative phosphorylation via three blocks of reactions, $V_{\text {oxidation, }} V_{\text {phosphorylation }}$ and proton leaks, linked by the protonmotive force, the common thermodynamic intermediate $(\Delta p){ }^{35}$

Once added into the respiratory medium, the mitochondria began to oxidize succinate and build up a membrane potential by the proton-pumping activity of the respiratory complexes, at a high value associated with state-4 respiration. The addition of limited amounts of ADP $(200 \mu \mathrm{M})$ induced phosphorylation-coupled respiration (state-3 respiration) and proton influx via the ATP synthase $F_{0}$ channel, leading to depolarization and a higher oxidative rate of around $71 \mathrm{nmol}$ $\mathrm{O}_{2} / \mathrm{min} / \mathrm{mg}$ protein (Figure $1 \mathrm{~b}$ ). In the case of control mitochondria, $\Delta \Psi_{\mathrm{m}}$ in state $4\left(\Delta \Psi_{\mathrm{m}} 4\right)$ was around $-174 \mathrm{mV}$. The respiratory control ratio $(\mathrm{RC})$, which corresponds to the ratio of the respiratory rate of the phosphorylation state $\left(V_{\mathrm{ox}_{3}}\right)$ to unphosphorylation state $\left(V_{\mathrm{ox}_{4}}\right)$, reflects the coupling of the mitochondria. Under our experimental conditions (in the presence of succinate and AP5A, i.e. P1,P5-di(adenosine-5')pentaphosphate, an inhibitor of kinase adenylate), the $\mathrm{RC}$ is normally over 4.5 . The phosphorylation yield, ADP/O, is around 1.5 for succinate-oxidizing mitochondria.

Despite showing similar RC and ADP/O, Bcl-2- or Bcl-XLdisplaying mitochondria exhibit a higher oxidation rate associated with an increase in the phosphorylation rate (Figure $1 \mathrm{~b}$ ). The ability of $\mathrm{Bcl}-2-$ or $\mathrm{Bcl}-\mathrm{XL}$-containing mitochondria to phosphorylate ADP at a faster rate may be linked to their enhanced capacity to exchange ADP/ATP. ${ }^{37} \mathrm{Bcl}-\mathrm{XL}$ acts similarly during a metabolic arrest induced by growth factor withdrawal. ${ }^{27}$ Under these conditions, Bcl-XL may allow growth factor-deprived cells to maintain sufficient ADP/ATP exchange to sustain coupled respiration.

Moreover, $\mathrm{Bcl}-2$ and $\mathrm{Bcl}-\mathrm{XL}$ mitochondria are less sensitive to $\mathrm{Ca}^{2+}$-induced PTP opening as revealed by the increasing dose of $\mathrm{Ca}^{2+}$ required to induce CsA-sensitive swelling (Figure 1c). Our results are consistent with a previous report in which $\mathrm{Bcl}-2$ potentiates maximum calcium uptake capacity in neuron-derived mitochondria. ${ }^{43}$ The calcium concentrations required to induce swelling of liver mitochondria are similar to those in neural cell mitochondria. The enhanced ability of mitochondria from $\mathrm{Bcl}-2$ and $\mathrm{Bcl}-\mathrm{XL}$-overexpressed cells to sequester large quantities of $\mathrm{Ca}^{2+}$ without any profound respiratory impairment provides a plausible explanation for the mechanism by which $\mathrm{Bcl}-2$ and $\mathrm{Bcl}-\mathrm{XL}$ inhibit certain forms of cell death.

On the other hand, the absence of Bax or Bak has no effect on mitochondrial bioenergetics. Indeed, $\mathrm{Bax}^{-1-}$ or $\mathrm{Bak}^{+/+}$ mitochondria exhibited bionergetic properties similar to control WT mitochondria (Figure 1b). 
a

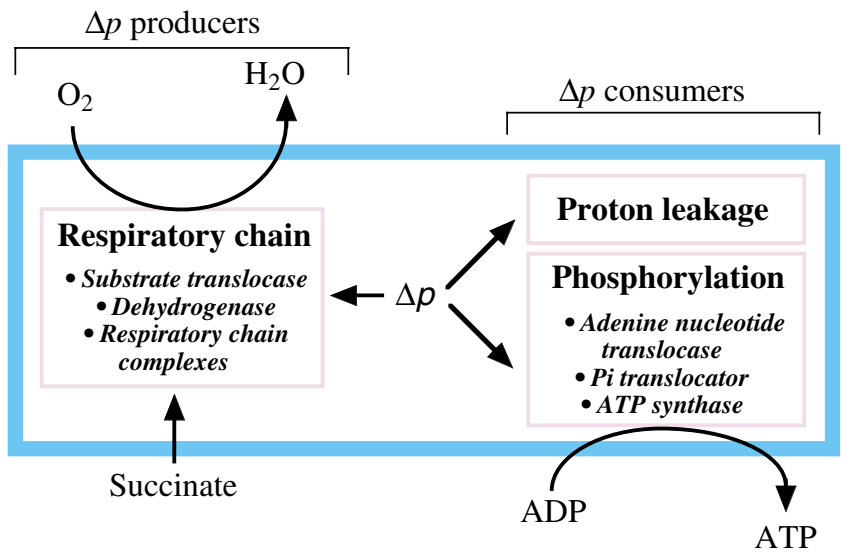

b

\begin{tabular}{|c|c|c|c|c|c|c|}
\hline Mitochondria & 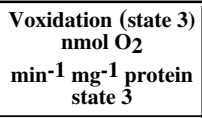 & $\mathrm{RC}^{1}$ & ADP/O & $\begin{array}{c}\text { Vphos. } \\
\text { nmol } \mathrm{H}^{+} \\
\text {min }^{-1} \mathbf{m g}^{-1} \text { protein }\end{array}$ & $\begin{array}{c}\Delta \psi \mathrm{m}^{3} \\
\text { state 4 } \\
(\mathrm{mV})\end{array}$ & $\begin{array}{l}\mathbf{C a}^{2+} \text {-induced } \\
\text { swelling }(\mu \mathbf{M})\end{array}$ \\
\hline Control & $71 \pm 4$ & $>4.5$ & $1.5 \pm 0.2$ & $220 \pm 5$ & $174 \pm 8$ & $250 \pm 9$ \\
\hline Bcl-2 & $85 \pm 5$ & $>4.5$ & $1.5 \pm 0.3$ & $255 \pm 9$ & $178 \pm 9$ & $300 \pm 10$ \\
\hline Bcl-XL & $84 \pm 4$ & $>4.5$ & $1.5 \pm 0.3$ & $251 \pm 8$ & $179 \pm 7$ & $292 \pm 7$ \\
\hline Bax $^{-/-}$ & $70 \pm 4$ & $>4.5$ & $1.4 \pm 0.4$ & $221 \pm 8$ & ND & ND \\
\hline Bak $^{-/-}$ & $69 \pm 5$ & $>4.5$ & $1.6 \pm 0.2$ & $223 \pm 7$ & ND & ND \\
\hline
\end{tabular}

c
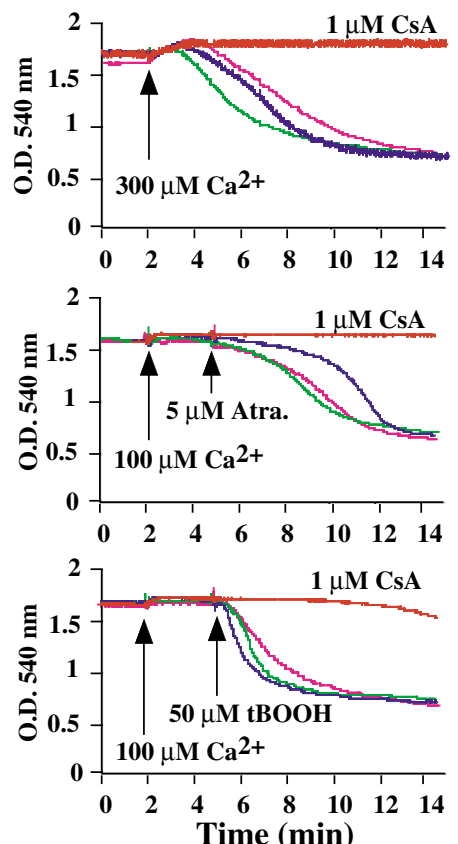

\begin{tabular}{|c|c|}
\hline $\begin{array}{l}\text { C57/B16 } \\
\mathrm{C} 57 / \mathrm{Bl6}+1 \mu \mathrm{M} \mathrm{CsA}\end{array}$ & $\begin{array}{ll} & \text { BCL-2 } \\
& \text { BCL-XL }\end{array}$ \\
\hline
\end{tabular}

Figure 1 Basic properties of control, Bcl-2, and Bcl-XL mitochondria. Oxidative phosphorylation in mouse liver mitochondria. The system shows all steps of the oxidative phosphorylation via three sets of reactions that were tested in (a), and are connected by the common thermodynamic intermediate $(\Delta p) .{ }^{41,42}(\mathbf{b})$ The table summarizes the main characteristics of the mitochondria (control, Bcl-2, Bcl-XL, $\mathrm{Bax}^{+/+}$and $\mathrm{Bax}^{-/-}$) used for the studies. (c) Opening of the permeability transition pore (PTP) by calcium, atractyloside, and ter-butyl hydroperoxide In C57/Bl6, Bcl-2 and Bcl-XL overexpressing mouse liver mitochondria are shown

\section{tBid disturbs mitochondrial bioenergetics: a process independent of Bax and Bak but inhibited by $\mathrm{Bcl}-2$ and $\mathrm{Bcl}-\mathrm{XL}$}

We determined the action of recombinant tBid on mitochondrial bioenergetic parameters by adding tBid in wild-type succinate-oxidizing mitochondria after a first transition of phosphorylation (Figure $2 \mathrm{~b}$ ). Adding $10 \mathrm{nM}$ of tBid immediately induces a $14 \mathrm{mV}$ decrease in $\Delta \Psi_{\mathrm{m}}$, associated with a slight increase in the respiratory rate by approximately $3 \mathrm{nmol}$ $\mathrm{O}_{2} / \mathrm{min} / \mathrm{mg}$ of mitochondrial protein (mild uncoupling). A lower concentration of tBid $(<1 \mathrm{nM})$ has no uncoupling capacity (data not shown). The effect of tBid on state-3 respiration parameters was determined. tBid induced an immediate decrease in the state- 3 respiratory rate by approximately $11 \mathrm{nmol} \mathrm{O}_{2} / \mathrm{min} / \mathrm{mg}$ of mitochondrial protein, associated with a decrease in the phosphorylation rate by around $63 \mathrm{nmole}$ ATP $/ \mathrm{min} / \mathrm{mg}$ of mitochondrial protein after the first ADP addition. As shown in Figure $2 b$, tBid acted in a timedependent manner. The inhibition in state-3 respiration and phosphorylation increased with time and marked $30 \%$ inhibition after $10 \mathrm{~min}$ incubation with tBid (Figure 2b).

Figure 2 Cleaved tBid inhibits ADP-stimulated oxygen respiration in mitochondria and is antagonized by Bcl-XL and BH3-only domain of tBid. Mitochondria (0.333 mg/ $\mathrm{ml}$ ) were incubated with respiratory buffer alone (a), or when indicated with various amounts of recombinant Bid (tBid) that has been cleaved with recombinant active caspase-8 (b) in a final volume of $3 \mathrm{ml}$. In (c), mitochondria from transgenic mice overexpressing Bcl-2 were used. (a) Recording of the oxidation rate (black line), mitochondrial membrane potential (green line) and phosphorylation rate (blue line) in control mitochondria. The numbers along the trace give the oxidation rate in nmol $\mathrm{O}_{2} / \mathrm{min} \mathrm{mg}$ protein (black), the potential in $\mathrm{mV}$ (green), and the phosphorylation rate in nmole ATP/min/mg of mitochondrial protein (blue). The arrows along the trace correspond to ADP $110 \mu \mathrm{M}$ additions unless otherwise noted. The uncoupler $\mathrm{mCICCP}(10 \mu \mathrm{M})$ is added at the end of the trace. (b) tBid (10 nM) was added directly after a first state-3/state-4 transition. Two subsequent ADP additions (110 $\mu \mathrm{M})$ were performed, followed by an addition of $10 \mu \mathrm{M}$ mCICCP. (c) Same as (a) with mitochondria overexpressing Bcl-2. (d and e) Histograms presenting the Bcl-2 (d) and Bcl- $\mathrm{XL}$ (e) inhibition of state-3 respiration counteracted by preincubation with the BH-3-domain peptide of tBid. Data presented were extracted from respiratory measurements with simultaneous recording of the mitochondrial membrane potential as shown in (a-c). In both cases, tBid BH3 peptides are used at concentrations (1-5 $\mu \mathrm{M})$ that did not cause apoptosis. (d) Oxidation rate in the presence of succinate of control BcP-2 mitochondria pretreated for $10 \mathrm{~min}$ with $10 \mathrm{nM}$ tBid. ADP $110 \mu \mathrm{M}$ was added after tBid addition into the closed glass vessel. (e) Same experiment in the presence of Bcl$\mathrm{XL}$ or Bcl-2 mitochondria. In (f), histograms of the oxidation rate in the presence of succinate of control mitochondria treated with $10 \mathrm{nM}$ tBid $\mathrm{G}_{\mathrm{G}} \mathrm{E}$ mutant Illm, and with $\mathrm{Bcl}-2$ or Bcl-XL mitochondria are shown. (g) Same experiments in the presence of Bax-or Bak-deficient mitochondria. For all the histograms from (d) to ( $g$ ), the oxidation rate is normalized as the percentage of the maximal oxidation. The $V_{\max }$ in the control mitochondria is of $74 \pm 4 \mathrm{nmol} / \mathrm{min} / \mathrm{mg}$ protein for c57/Bl6 mitochondria and of $84 \pm 4$ and $85 \pm 5 \mathrm{nmol} \mathrm{O}_{2} / \mathrm{min} / \mathrm{mg} \mathrm{O}_{2}$ for the mitochondria purified from Bcl-XL and Bcl-2 transgenic mice, respectively, whereas it is of $70 \pm 4$ and $69 \pm 5$ for Bax ${ }^{-1-}$ and Bak ${ }^{-1-}$ mitochondria respectively 
a

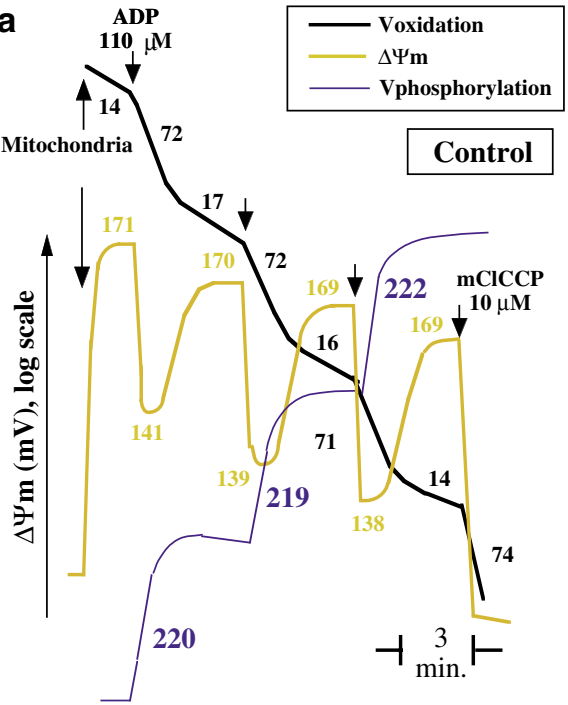

b

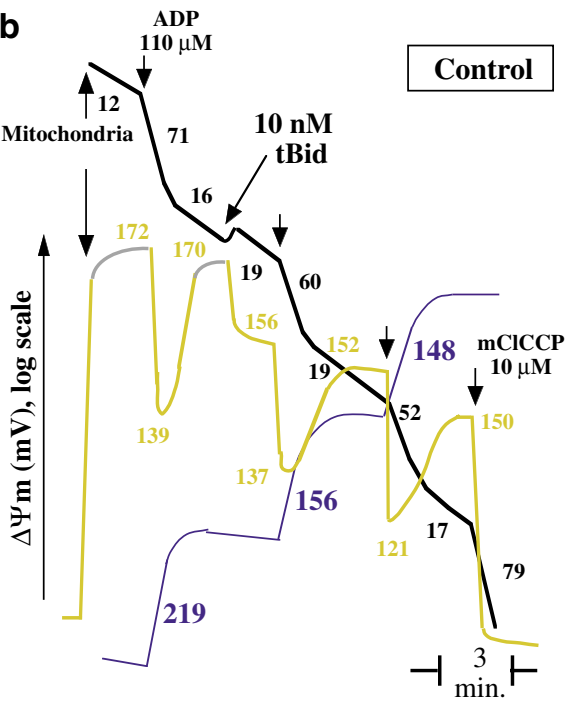

c

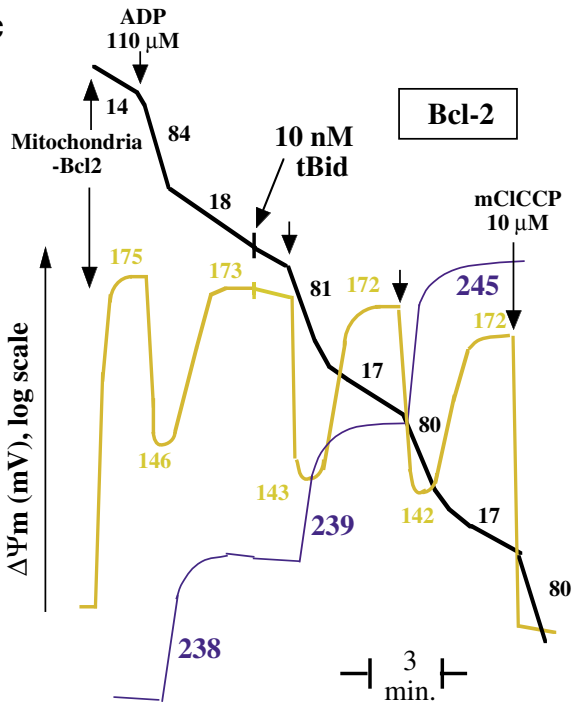

d
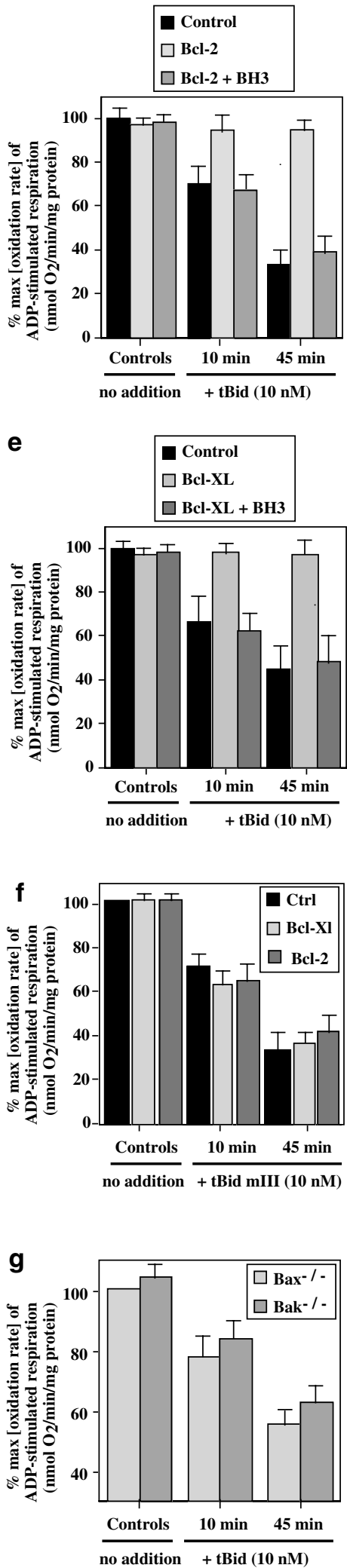
Inhibition of both ADP-stimulated respiration and phosphorylation rate also increased after a second ADP addition and reached $60 \%$ inhibition after $30 \mathrm{~min}$ (not shown).

Three hypotheses could explain these inhibitions: (i) tBid might inhibit the respiratory chain (generator of proton gradient) but this hypothesis is inconsistent with the finding that $t B i d$ has no effect on the $\mathrm{mCICCP}$-uncoupled respiration rate (Figure 2b), (ii) tBid may affect the machinery of phosphorylation (consumer of proton gradient) or (iii) tBid may cause increase in proton leaks by one way or another leading to a decrease in proton gradient.

As shown in Figure $2 \mathrm{c}-\mathrm{e}$, tBid is unable to disrupt any bioenergetic parameters $\left(\Delta \Psi_{\mathrm{m}}\right.$, respiration and phosphorylation rate) in $\mathrm{Bcl}-2-$ and $\mathrm{Bcl}-\mathrm{XL}$-expressing mitochondria. Indeed, $\mathrm{Bcl}-2$ and $\mathrm{Bcl}-\mathrm{XL}$ completely protect mitochondria from tBid even after $10 \mathrm{~min}$ incubation. On the other hand, injecting a noncytotoxic dose of $\mathrm{tBid} \mathrm{BH} 3$ peptide (1-5 $\mu \mathrm{M})$ together with tBid completely restored the effect on tBid in Bcl-2 and Bcl-XL mitochondria. The same results were obtained using $\mathrm{BH} 3$ peptide derived from Bax or Bak (data not shown).

Our results suggest that $\mathrm{Bcl}-2$ and $\mathrm{Bcl}-\mathrm{XL}$ protect mitochondria from bioenergetic alterations through the interaction with the $\mathrm{BH} 3$ domain of $\mathrm{tBid}$. We therefore investigated the effects of $\mathrm{BH} 3$ mutation on tBid-induced alterations of mitochondrial physiology. To this end, we used the tBid mutant mIII (tBidG94E), which is unable to interact with either proapoptotic (Bax and Bak) or antiapoptotic (Bcl-XL and $\mathrm{Bcl}-2)$ proteins. Adding $10 \mathrm{nM}$ of mutant tBid mlll inhibited ADP-stimulated respiration to the same level in control mitochondria as tBid (Figure 2f), suggesting that the interaction of tBid with other apoptotic factors like Bax or Bak is not required for inhibition of ADP-stimulated respiration.

Moreover, the effect of tBid mlll was maintained in Bcl-2 and $\mathrm{Bcl}-\mathrm{XL}$ mitochondria and in mitochondria purified from bax ${ }^{-1-}$ and bak $^{-1-}$ mice (Figure $2 \mathrm{~g}$ ).

Taken together, these results show that tBid can disturb mitochondrial bioenergetics independently of Bax and Bak at least during the time of its primary action, and that Bcl-2 and $\mathrm{Bcl}-\mathrm{XL}$ protect mitochondria by interacting with the $\mathrm{BH} 3$ domain of tBid.

\section{tBid and tBid IIIm localize at the mitochondrial membrane level and induce a delayed conformational change and oligomerization of Bak in vitro}

The treatment of Percoll-purified mitochondria with tBid and the irreversible cross-linker $\mathrm{BMH}$ for $30 \mathrm{~min}$ revealed that the $\mathrm{BMH}$ shifted Bak into distinct complexes of approximately $48 \mathrm{kDa}$ (major species), and $72 \mathrm{kDa}$ (minor species) and a $96 \mathrm{kDa}$ band (not observed on these gels) (Figure 3a). These shifted bands did not appear before $30 \mathrm{~min}$ incubation with tBid or if the tbid IIIm was used instead of tBid, consistent with the inability of tBid IIIm to interact with Bak.

Figure 3b (lower panel) demonstrated that tBid and tBid IIIm colocalized to the mitochondrial compartment, whereas tBid lacking the alpha helices $\mathrm{H} 6$ and $\mathrm{H} 7$ did not. The upper panel corresponds to the fluorescence spectrum of EYFP (empty vector) or CMXRos (mitochondrial membrane potential measurements).

\section{tBid inhibits ADP-stimulated respiration as a result of the inhibition of the ADPIATP exchange}

Mitochondria incubated with tBid (10 nM) (Figure 4a) or with atractyloside for $45 \mathrm{~min}$ (Figure $4 \mathrm{~b}$ ) displayed a similar level of inhibition of ADP-stimulated respiration, suggesting that inhibition of the phosphorylation machinery (ANT in this case) may be responsible for the tBid effect. The time required for the insertion of tBid into the mitochondrial membrane and its stabilization may explain why complete inhibition occurred only after $45 \mathrm{~min}$, although the initial action on the mitochondrial respiratory activity in the presence of ADP was detectable almost immediately (3-5 min, Figure $2 b$ ). Incubation of mitochondria with exogenous cytochrome $c$ did not change mitochondrial respiration inhibition by tBid, therefore demonstrating that the inhibition is not due to an early cytochrome $c$ release (Figure $4 c$ ).

We investigated the effect of tBid on ADP/ATP exchange in control mitochondria and in purified mitoplasts in order to exclude a possible involvement of the porin VDAC in this process (Figure 4d, e). tBid and tBid IIIm caused a significant reduction in ATP/ADP exchange in both control mitochondria and mitoplasts (around 50\%), demonstrating that tBid is able to partially inhibit ADP/ATP exchange by inhibiting the ANT (Figure 4e). This is associated with an increase in the $K_{\mathrm{m}}$ for ADP (decrease in affinity) and a decrease in the $V_{\text {max }}$ of the ATP/ADP exchange (decrease in activity), characterizing an inhibition known as mixed or noncompetitive. This suggests that tBid affects both the ADP binding and the catalytic site of the ANT translocator. Also, consistent with our previous results, ${ }^{37}$ ATP/ADP exchange is increased by $40 \%$ in Bcl-2 or $\mathrm{Bcl}-\mathrm{XL}$ mitochondria (Figure $4 \mathrm{e}$ ). Since components of the outer mitochondrial membrane are not involved in this process, these results suggest that tBid may have direct access to the vicinity of the ANT, consolidating the hypothesis that tBid is able to interact directly at the contact sites by specific interaction with cardiolipin. ${ }^{17}$

\section{tBid interacts specifically with cardiolipin and stabilizes artificial lipid monolayer into microdomains}

To elucidate the role of cardiolipin in this process, we determined the action of recombinant tBid in $\Delta \mathrm{crd} 1$, a yeast strain deficient in cardiolipin due to a disruption of CRD1, the structural gene encoding cardiolipin synthase. First, we compared mitochondrial function in the $\Delta \mathrm{crd} 1$ mutant and the isogenic wild type (Table 1 ). $\Delta$ crd1 mutant displayed a slight decrease in the mitochondrial function. In fact, absence of cardiolipin induced an increase in the oxidation rate in state 4 associated with a decrease in state 3 , associated with inhibition of ATP production, hence decreasing $\mathrm{RC}$ from 5.1 to 1.6. Nevertheless, the effect of tBid on the bioenergetic functions of $\Delta$ crd1 mitochondria was studied.

Incubation of wild-type yeast mitochondria with tBid $(20 \mathrm{nM})$ for $20 \mathrm{~min}$ reduced the $\mathrm{NADH}$-sustained state-3 respiration from 650 to $470 \mathrm{nmol} \mathrm{O}_{2} / \mathrm{min} / \mathrm{mg}$ protein (Figure $5 \mathrm{a}$, b) and the 
a
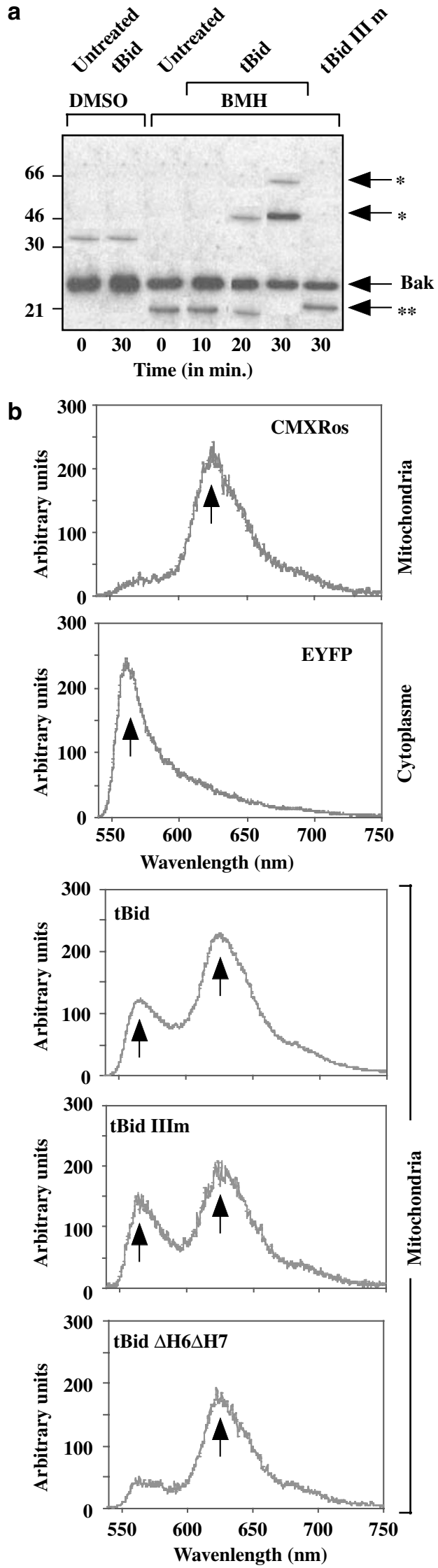

phosphorylation rate from 866 to $716 \mathrm{nmol}$ ATP/min $\mathrm{mg}$ of mitochondrial protein. By analogy with liver mitochondria, tBid acted in a time-dependent manner (Table 1). Indeed, after a 45-min incubation, ADP-stimulated respiration inhibition increased by $76 \%$ coinciding with complete inhibition of ATP production (Figure $5 \mathrm{c}$ ). No effect on state-4 respiration was obtained in yeast. Since yeast is deficient in proapoptotic Bcl-2 family proteins, these results confirm our previous observation that tBid is able to disturb mitochondrial function independently of Bax and Bak. None of these changes were observed in the cardiolipin null-mutant yeast (Table 1 and Figure 5c) even after $45 \mathrm{~min}$ of incubation with tBid.

We also asked whether cardiolipin was only required for tBid binding or whether it was also involved in the inhibition of ANT by tBid. Monolayers of zwitterionic PC and negatively charged cardiolipin were spread at an initial surface pressure of $20 \mathrm{mN} / \mathrm{m}$. Injection of tBid beneath them resulted in a large increase in surface pressure only in the presence of $C L$ and as a function of the amount of tBid injected into the subphase (Figure $5 \mathrm{~d}$ ). Moreover, the increase in pressure was correlated with the amount of cardiolipin in the monolayer. This biophysical approach shows that cardiolipins are essential for tBid binding. tBid is only inserted in the presence of cardiolipins, and the binding efficiency is optimized when the monolayer contains approximately $25 \%$ cardiolipin, which corresponds to the natural composition of the mitochondrial inner membrane.

We also investigated the consequences of tBid-cardiolipin interaction on the phospholipid organization by epifluorescence microscopy. Figure 5e shows a set of images recorded at different times following injection of tBid into the subphase buffer. The pure cardiolipin monolayer gave a uniform fluorescent liquid-expanded phase before tBid insertion $(t=0)$. Once tBid was added, transition to the liquidcondensed phase occurred, as indicated by the appearance of dark probe-excluded domains. These domains had a relatively homogeneous appearance after $15 \mathrm{~min}$, and were distributed uniformly throughout the visual field (Figure 5e). Thus, tBid interacts specifically with cardiolipin and stabilizes the artificial lipid monolayer into microdomains. Modification of cardiolipin organization into microdomains at the mitochondrial level may affect the function of the proteins inserted into such membranes (like ANT) and could thus lead to a decrease in ADP/ATP translocator activity.

Figure 3 tBid and tBid IIIm induces conformational change and eventually oligomerization of Bak in vitro and also localized at the mitochondrial membrane level. (a) The IVT tBid and IVT tBid IIIm proteins were targeted to mitochondria. Mitochondria were then treated with a DMSO control buffer or with $10 \mathrm{mM} \mathrm{BMH}$ crosslinker. The pattern of crosslinked Bak was determined by an anti-bak Western blot. $\left(^{*}\right)$ Higher molecular mass BMH-crosslinked Bax complex. $\left(^{* *}\right)$ Intramolecular crosslinked Bax monomer displayed faster motility. (b) The upper panel shows the spectra of mitochondria stained with CMXRos, whereas the lower panel designed spectrum of a cytoplasmic EYFP (empty vector). The arrows designed the EYFP and CMXRos fluorescence when significant. In (c), the upper panel relates to tBid binding and localization to mitochondria (two arrows) and the middle panel relates to tBid IIIm binding to mitochondria (two arrows), whereas the lower panel relates to tBid $\Delta \mathrm{H} 6 \Delta \mathrm{H} 7$ construct, which does not bind to mitochondria (only an arrow related to CMXRos staining) 
a

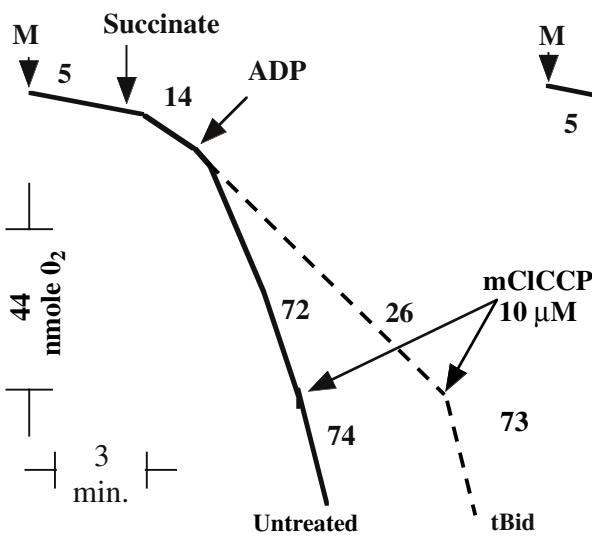

d

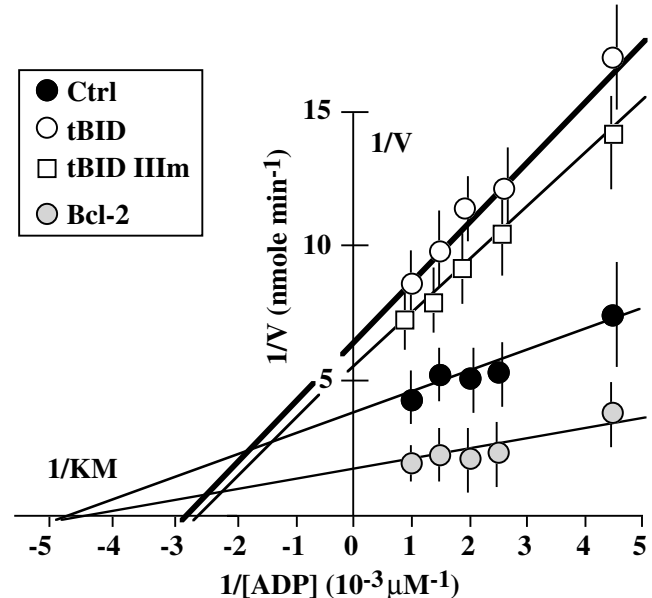

C tBID + exogenous cytochrome $c$ Succinate

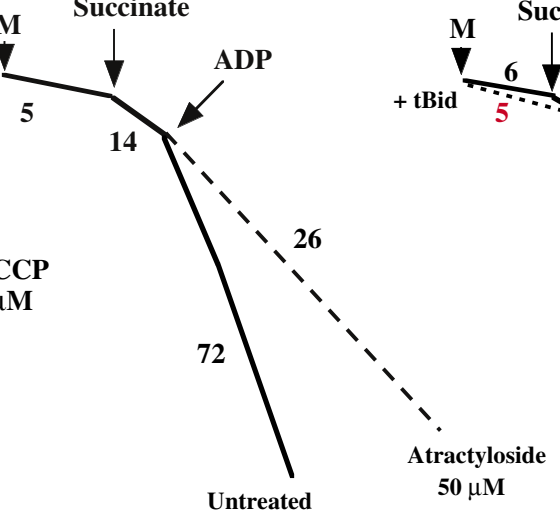

uccinate<smiles>[TeH4]=[Pt]</smiles>

14

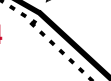

DP

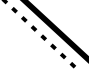

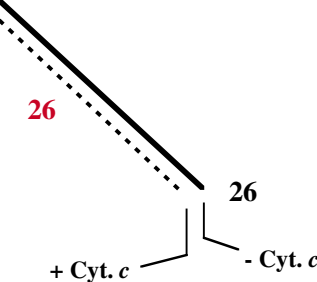

e

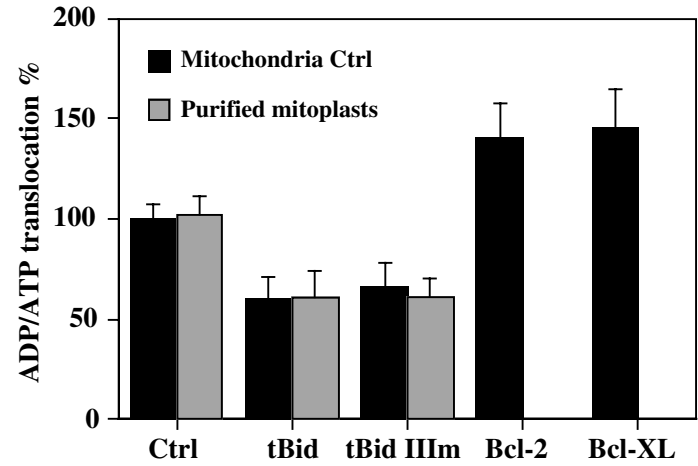

Figure 4 tBid-inhibition of ADP-stimulated respiration and ADP/ATP exchange. (a) Effect of tBid on isolated mitochondria. Mitochondria (0.666 mg) were preincubated with buffer alone (black line), or with $10 \mathrm{nM}$ of recombinant tBid (hatched line) in a final volume of $150 \mu \mathrm{l}$ respiratory medium. Succinate $5 \mathrm{mM}$ and $110 \mu \mathrm{M}$ ADP were added into the glass reaction vessel at the indicated time points. In (b), mitochondria were preincubated with atractyloside $(50 \mu \mathrm{M}$ final) prior to transfer into the glass vessel (hatched line) and could be compared to the untreated sample (black line). The reaction was incubated for $10 \mathrm{~min}$ at $25^{\circ} \mathrm{C}$. In (c), mitochondria from mice liver control treated with or without cytochrome $c$ are shown. An amount of $80 \mu \mathrm{g}$ of horse cytochrome $c$ was added to the aliquots of $150 \mu$ l reaction mixture containing mitochondria with $10 \mathrm{nM}$ tBid prior to adding the mixture into the glass vessel. In (d), the effect of tBid on isolated mitochondria is shown. Mitochondria from mouse liver (control, Ctrl) or preincubated with recombinant tBid protein ( $1 \mu \mathrm{g}$ tBid per $10 \mathrm{mg}$ mitochondrial protein in $500 \mu \mathrm{l}$ buffer) were loaded with ${ }^{3} \mathrm{H}$-labelled ATP, washed and incubated with variable doses of nonradioactive ADP, followed by the determination of ATP release into the mitochondrial supernatant. An experiment with Bcl-2 purified mitochondria is also present as a control of the acceleration of the ADP/ATP translocation in these conditions. (e) Comparison between the effects of $10 \mathrm{nM}$ tBid or $10 \mathrm{nM}$ tBid $_{\text {G94E }}$ mutant IIIm on control mitochondria versus purified mitoplasts. Also, comparison with Bcl-2 and Bcl-XL mitochondria is shown

Table 1 Respiratory characteristics of mitochondria from wild-type yeast and cardiolipin null-mutant yeast

\begin{tabular}{|c|c|c|c|c|}
\hline \multirow[b]{2}{*}{ Yeast mitochondria } & \multicolumn{2}{|c|}{$V_{\text {oxidation }}\left(\mathrm{nmol} \mathrm{O}_{2} / \mathrm{min} \mathrm{mg}\right.$ protein) } & \multirow[b]{2}{*}{$\mathrm{RCR}^{\mathrm{a}}$} & \multirow[b]{2}{*}{ Inhibition \% (state 3) } \\
\hline & State-3 & State 4 & & \\
\hline $\begin{array}{l}\text { Control }\left(\mathrm{CL}^{+}\right)^{\mathrm{b}} \\
\text { tBid }(5 \mathrm{~min})+\text { ATP } \\
\text { tBid }(10 \mathrm{~min})+\text { ATP } \\
\text { tBid }(20 \mathrm{~min})+\text { ATP } \\
\text { tBid }(45 \mathrm{~min})+\text { ATP }\end{array}$ & $\begin{array}{l}670 \pm 45 \\
611 \pm 38 \\
528 \pm 29 \\
474 \pm 15 \\
158 \pm 9\end{array}$ & $\begin{array}{l}131 \pm 6 \\
134 \pm 6 \\
139 \pm 6 \\
147 \pm 5 \\
152 \pm 6\end{array}$ & $\begin{array}{l}5.1 \\
4.6 \\
3.8 \\
3.2 \\
1.04\end{array}$ & $\begin{array}{l}0 \\
8.8 \\
21.2 \\
29.3 \\
76.5\end{array}$ \\
\hline $\begin{array}{l}\text { Control }\left(\mathrm{CL}^{-}\right) \\
\text {tBid }(20 \mathrm{~min})+\text { ATP }\end{array}$ & $\begin{array}{l}480 \pm 16 \\
478 \pm 16\end{array}$ & $\begin{array}{l}306 \pm 12 \\
302 \pm 13\end{array}$ & $\begin{array}{l}1.6 \\
1.6\end{array}$ & $\begin{array}{l}0 \\
0\end{array}$ \\
\hline
\end{tabular}

Mitochondria were preincubated with $200 \mu \mathrm{M}$ ATP and $10 \mathrm{nM}$ tBid. NADH, $1 \mathrm{mM}$; Pi, $10 \mathrm{mM}$. ${ }^{\mathrm{a}} \mathrm{RC}$, respiratory control (ratio of state-3 to state-4 respiration). Oxidation rate in $\mathrm{nmol} \mathrm{O}_{2} /$ min $\mathrm{mg}$ protein. ${ }^{\mathrm{b}}$ Cardiolipin present, $\mathrm{CL}^{+}$; cardiolipin absent, $\mathrm{CL}^{-} .{ }^{\mathrm{C}} \mathrm{ATP} 200 \mu \mathrm{M}$ added with $10 \mathrm{nM}$ tBid during the preincubation. 

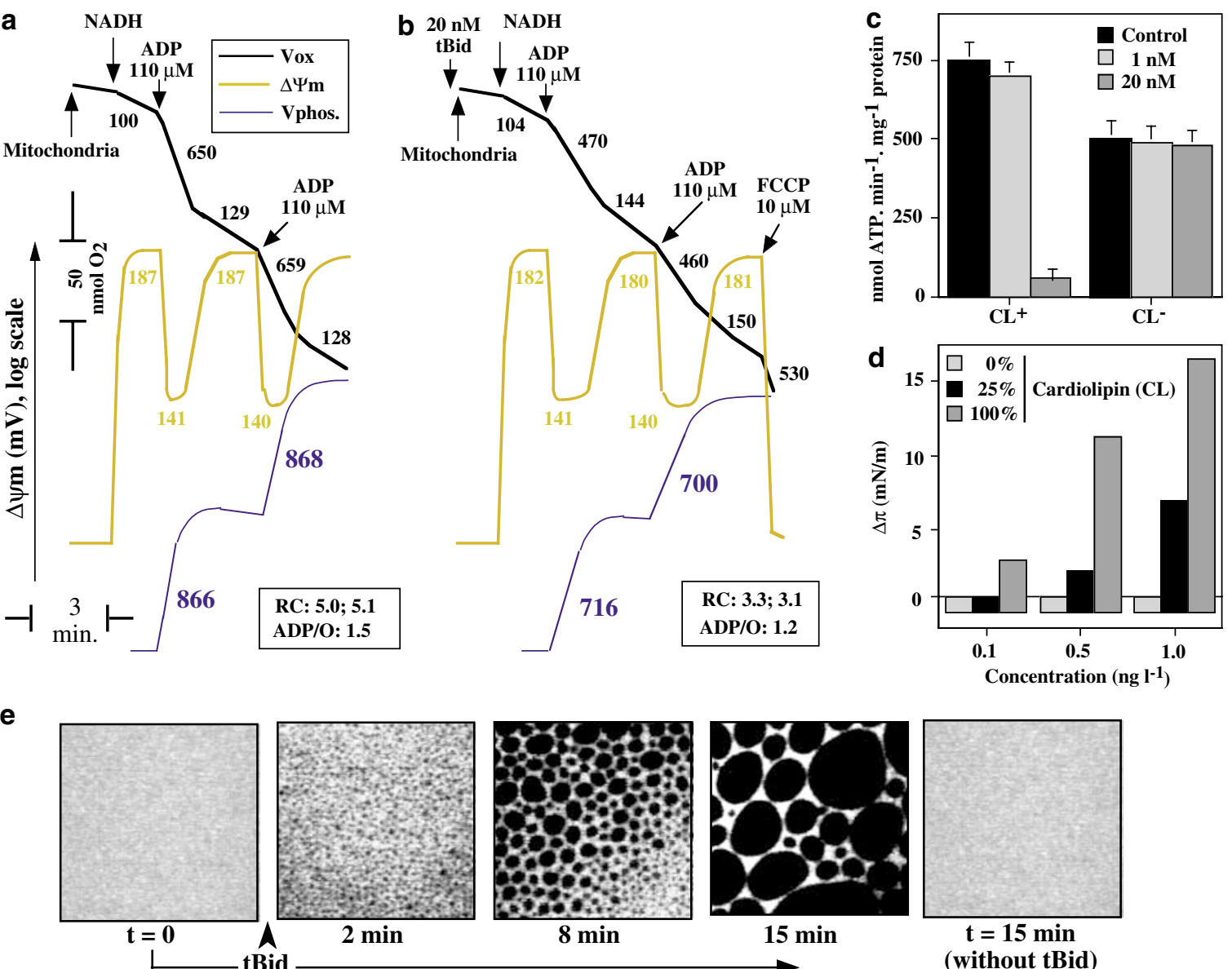

$\widehat{\text { Bid }}$

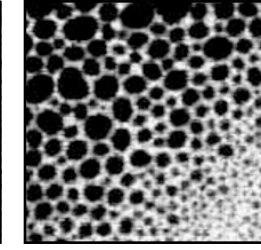

$8 \mathrm{~min}$

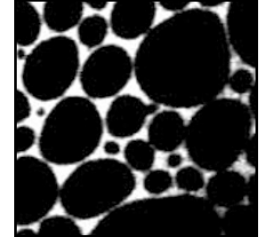

15 min

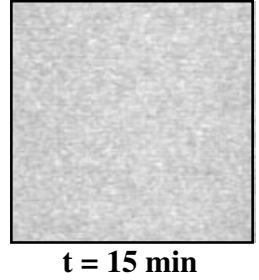

(without tBid)

Figure 5 Studies with yeast mitochondria issued from wild-type and $\Delta \mathrm{crd} 1$ cardiolipin null-mutant yeast strains and interaction of tBid with preformed monolayers of cardiolipin (CL). (a) Respiratory trace of control yeast mitochondria (with cardiolipin, $\mathrm{CL}^{+}$) and respiratory rate in the presence of $20 \mathrm{nM}$ tBid preincubated for 20 min before placing the mixture in the oxygen chamber (b). Respiratory rate is indicated along the trace in nmole $\mathrm{O}_{2} / \mathrm{min} \mathrm{mg}$ protein. (c) ATP production in the presence of $1 \mathrm{mM}$ ADP in control mitochondria $\left(\mathrm{CL}^{+}\right)$and mitochondria from cardiolipin synthase null mutant ( $\mathrm{CL}^{-}$) in the presence (45 min preincubation) of 1 or $20 \mathrm{nM}$ of tBid. The results are given as nmol ATP produced $/ \mathrm{min} / \mathrm{mg}$ protein. (d) Monolayer surface pressure increase as a function of the concentration of tBid in the subphase. Monolayers of DPPC, CL and CL/DPPC $25 / 75$ were formed at an initial pressure of $20 \mathrm{mN} / \mathrm{m}$. (e) Fluorescence microscope photographs as a function of time of a monolayer consisting of $\mathrm{CL}$ and $0.5 \mathrm{~mol} \% \mathrm{NBDPG}$ in the liquid-expanded phase $(t=0)$ and after injection of tBid in the subphase

\section{tBid released cytochrome $c$ as a result of transient openings of PTP}

Finally, we investigated the effect of tBid on the permeability of the outer membrane to cytochrome $c$. The release of cytochrome $c$ was measured under various conditions (Figure $6 a-d)$. tBid released a maximal amount of cytochrome $c$ after a 60-min incubation, while atractyloside and mCICCP (uncoupling agent) did not (Figure 6a). Moreover, even at 10-30 min, when there is an increased release of entrapped calcein, a significant release of cytochrome $c$ is not seen (Figure $6 c$ and d). This late event of cytochrome $c$ release is partly inhibited by CsA (Figure 6b), suggesting a partial involvement of PTP in this process. Moreover, the tBid IIIm mutant was also able to release cytochrome $c$ to a similar extent (Figure $6 \mathrm{~b}$ and d). The BH3 domain appears not to be involved in the long-lasting cytochrome $c$-releasing activity of tBid.

It was reported that a low concentration of tBid $(1 \mathrm{nmol} / \mathrm{mg}$ protein) failed to induce swelling and immediate depolariza- tion of mitochondria, ${ }^{19,38,39,44}$ whereas a small depolarization, which requires a longer incubation time, was reported (i.e., $60 \mathrm{~min}) .{ }^{19}$ We show in this report that a higher concentration of tBid $(10 \mathrm{nM})$ induced a small but significant depolarization (5-10 mV) (Figure 2b) but not swelling (data not shown). However, PTP opening can either be associated ${ }^{45}$ or not with a drop in $\Delta \Psi_{\mathrm{m}}$ and/or mitochondrial swelling. ${ }^{46}$

These transient openings can be measured by monitoring the release of calcein trapped in the mitochondrial matrix. ${ }^{47}$ tBid increased the release of calcein from the matrix in a timedependent manner (Figure 6e), an event only partly inhibited by the PTP pore inhibitors CsA and BA. Similar results were obtained using the BH3 mutant, Bid IIIm (G94E) (Figure 6f), whereas $\mathrm{Bcl}-2$ and $\mathrm{Bcl}-\mathrm{XL}$ mitochondria were both completely insensitive to tBid. Bid IIIm (G94E) released calcein despite the presence of $\mathrm{Bcl}-2$ and $\mathrm{Bcl}-\mathrm{XL}$ (Figure $6 \mathrm{~g}$ ), suggesting that $\mathrm{BH} 3$ domain is not involved in the transient PTP opening activity induced by tBid. The time-dependent increase in PTP opening and closure induced by tBid are compatible with the 

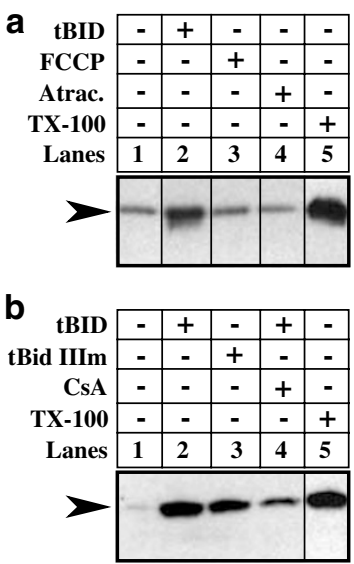

e

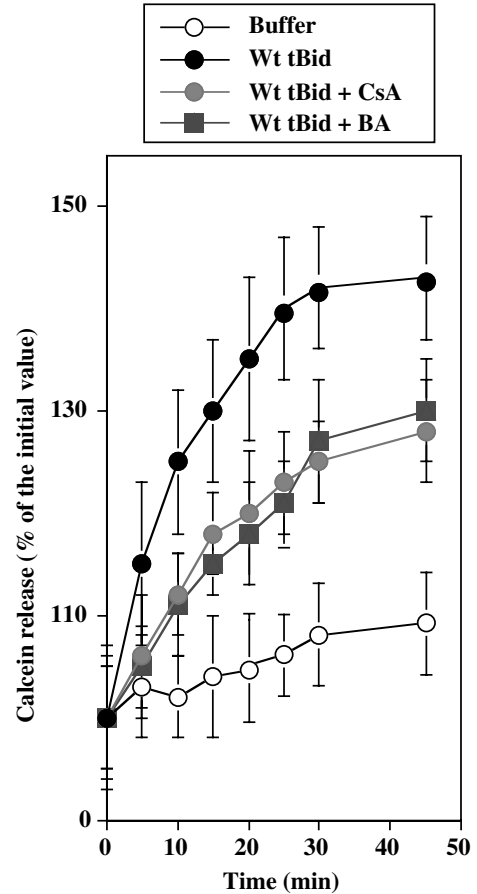

C

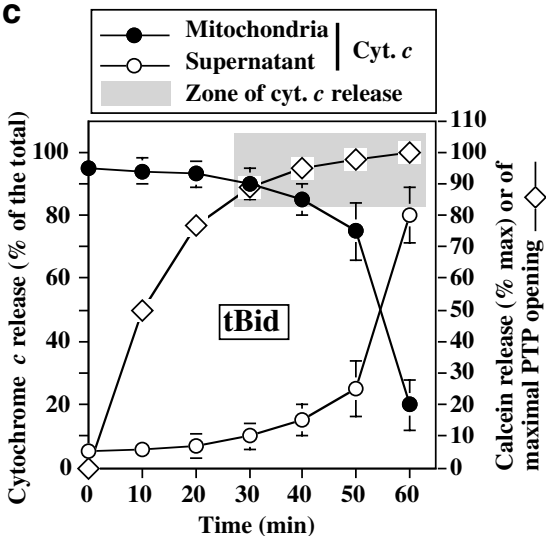

$\mathbf{f}$
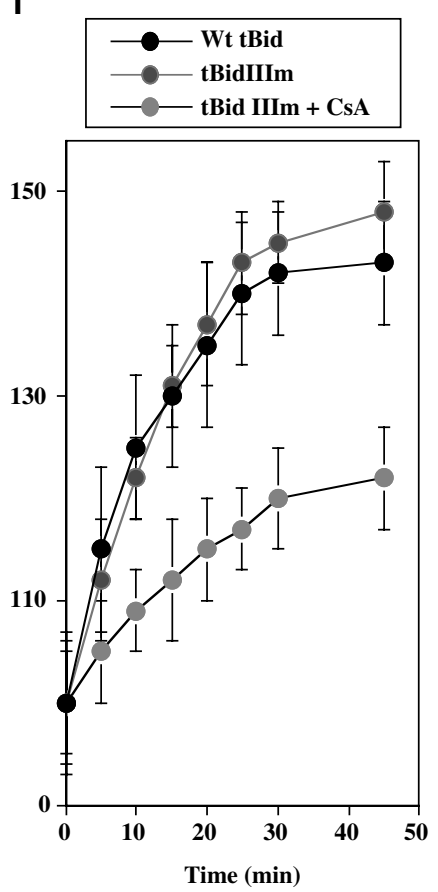

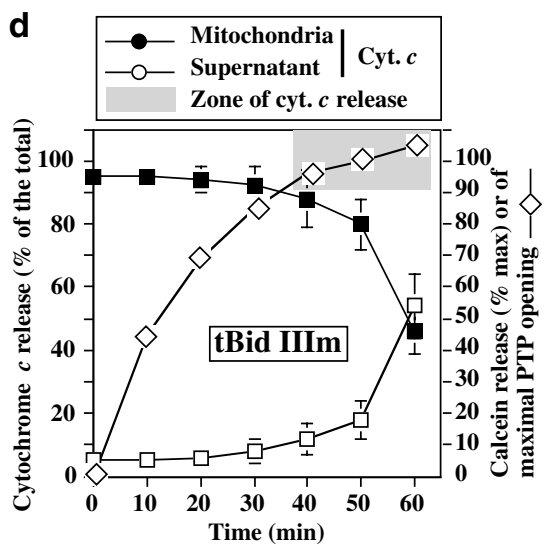

g
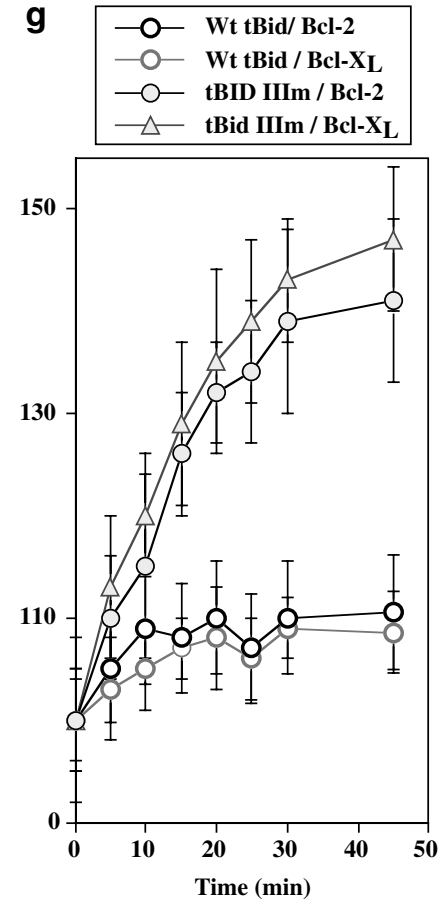

Figure 6 Transient opening of the mitochondrial transition pore and release o $f$ cytochrome $c$. In (a) and (b), measurement of cytochrome $c$ released in the mitochondrial supernatant in different conditions is shown. In (a), mitochondria were preincubated with buffer alone (lane 1), or with $10 \mathrm{nmol}$ recombinant tBid (lane 2), or with $5 \mu \mathrm{M}$ atractyloside (lane 4), or with $0.5 \%$ Triton X-100 (lane 5) in a final volume of $150 \mu \mathrm{l}$ respiratory medium. The reaction was incubated for 60 min at $25^{\circ} \mathrm{C}$. After incubation, aliquots of $150 \mu \mathrm{l}$ reaction mixture were added to $1.4850 \mathrm{ml}$ of respiratory medium in a glass reaction vessel for measurements of oxygen utilization as described in the Materials and Methods. At the indicated time points, $5 \mathrm{mM}$ succinate and $110 \mu \mathrm{M}$ ADP were added to the glass reaction vessel. In (b), mitochondria were preincubated with buffer alone (lane 1), or with $10 \mathrm{nmol}$ recombinant-cleaved tBid (lane 2), or with the Bid mutant G94E devoid of the BH3 domain (lane 3), or incubated with tBid in presence of $1 \mathrm{mM} \mathrm{CsA}$ (lane 4) or with $0.5 \%$ Triton X-100 (lane 5). In (c) and (d), time course (on $60 \mathrm{~min}$ ) of cytochrome crelease versus calcein release in the presence of $10 \mathrm{nM}$ tBid and tBid IIIm, respectively, is shown. The gray zone represents the time where the cytochrome $c$ release and the PTP pore is in a range of importance; above this zone event if the calcein release is significant, the cytochrome $c$ release does not reach a significant level. In (e), the effects of CsA (1 $\mu \mathrm{M})$ and BA $(5 \mu \mathrm{M})$ on tBid-induced calcein release are shown. Mitochondria were incubated without (buffer, open circles) or with tBid (solid circles); BA (solid triangles) or CsA (red stippled circles) were added in some cases. Mitochondria were preincubated with CsA or BA for 2 min. Data are the means of five independent experiments. An amount of $5 \mathrm{nM}$ tBid was used in all experiments. In (f), same as for (c), tBID IIIm (10 nM) (red stippled circles) with tBid is used (solid circles) as a control red stippled circles. CsA inhibition of calcein release. In (g), influence of Bcl-2 and Bcl-XL on tBid and tBid Illm-induced calcein release. Solid circles: tBid (10 nM) on Bcl-2 mitochondria; stippled circles; Bcl-XL mitochondria. The effect of tBid IIIm (10 nM) on Bcl-2 (yellow closed circles) and Bcl-XL (yellow triangles) mitochondria is shown

cytochrome $c$ release observed from 60-min incubation (Figure 6a and b).

Concerning the possible involvement of the PTP in the tBid effect, we tested the effects of CsA on the mitochondrial respiration in the presence of tBid or tBid IIIm. No effect of
CsA either on the state-3 inhibition or on the slight increase in state-4 respiration, which has been described (Figure 2b), was observed (results not shown). We cannot exclude the possibility that CsA may have a certain effect at $60 \mathrm{~min}$. In our conditions, CsA clearly inhibited $50-60 \%$ of calcein release 
(Figure $6 e$ and f), suggesting that another type of membrane permeability, which is CsA-insensitive, should be taken into account. Such permeability might be related to reorganization of the mitochondrial membrane cardiolipin during its interaction with tBid or tBid IIIm.

\section{Discussion}

Scorrano et al. ${ }^{19}$ recently demonstrated that tBid induces a remodelling of mitochondrial structure in vitro leading to unravelling of the cristae and exposure of cytochrome $c$. This reorganization event does not require the $\mathrm{BH} 3$ domain of $t B i d$ and is independent of Bak and slightly inhibited by CsA.

We show here for the first time that the binding of tBid to mitochondrial membrane immediately perturbs mitochondrial respiratory function. tBid is able to inhibit ADP-stimulated respiration and phosphorylation rate, independently of Bak and Bax, in mice and yeast mitochondria.

Our results, obtained with lipid monolayers, showed that cardiolipins are essential for tBid binding and raised the question as to how tBid interact with the contact sites, since cardiolipins are located in the inner membrane. The remodelling of the cristae ${ }^{19}$ and our results describing bioenergetics mitochondrial perturbations, which take place in a similar time scale, strongly suggest that tBid has an effect on the inner membrane. Moreover, tBid may bind to the contact sites ${ }^{17,18}$ and disrupt the membrane curvature. ${ }^{20}$ At the contact sites, cardiolipins and phosphatidylethanolamines adopt a hexagonal $\mathrm{H}_{\|}$configuration, ${ }^{21,22}$ so that over $45 \%$ of the endogenous phospholipids at the contact sites can adopt a nonbilayer configuration. It is evident that because of their unique chemical structure and the relative polymorphic phase behavior, cardiolipins have easy access to the outer mitochondrial membrane. ${ }^{23,24}$ Cardiolipins at the contact site might be accessible to tBid. tBid may interact with contact sites and induce the reorganization of phospholipids into microdomains (especially cardiolipin). Specific binding of cardiolipin to the ADP/ATP translocator has already been reported and the monitoring of reconstituted carrier activity has revealed that this interaction is required for its activity. ${ }^{25,26}$ It is conceivable that tBid indirectly influences the activity of ANT by redistributing phospholipids.

The observed transient PTP opening induced by tBid seems to be coordinated with remodelling of the cristae, mobilization of cytochrome $c$ stores from the cristae, and the final release of cytochrome $c$ due to permeabilization of the outer membrane, three events partly inhibited by CsA and BA. ${ }^{19}$

We demonstrated that tBid and tBid IIIm colocalized at the mitochondrial membrane but while tBid interacts with Bak, tBid IIIm did not. ${ }^{27}$ We also showed that the deletion of the $\mathrm{H} 6 \mathrm{H} 7$ alpha helices totally abolished both tBid and tBid IIIm targeting to the mitochondria. The experiment using Bid IIIm (G94E) and tBid BH3 provides the first evidence that the $\mathrm{BH} 3$ domain of tBid is involved neither in the disruption of mitochondrial bioenergetics nor in cytochrome $c$ release.

We believe that our results reinforce the recent discovery of the changes in mitochondrial structure induced by tBid, ${ }^{19}$ an observation made at the same time scale (15-20 min). These
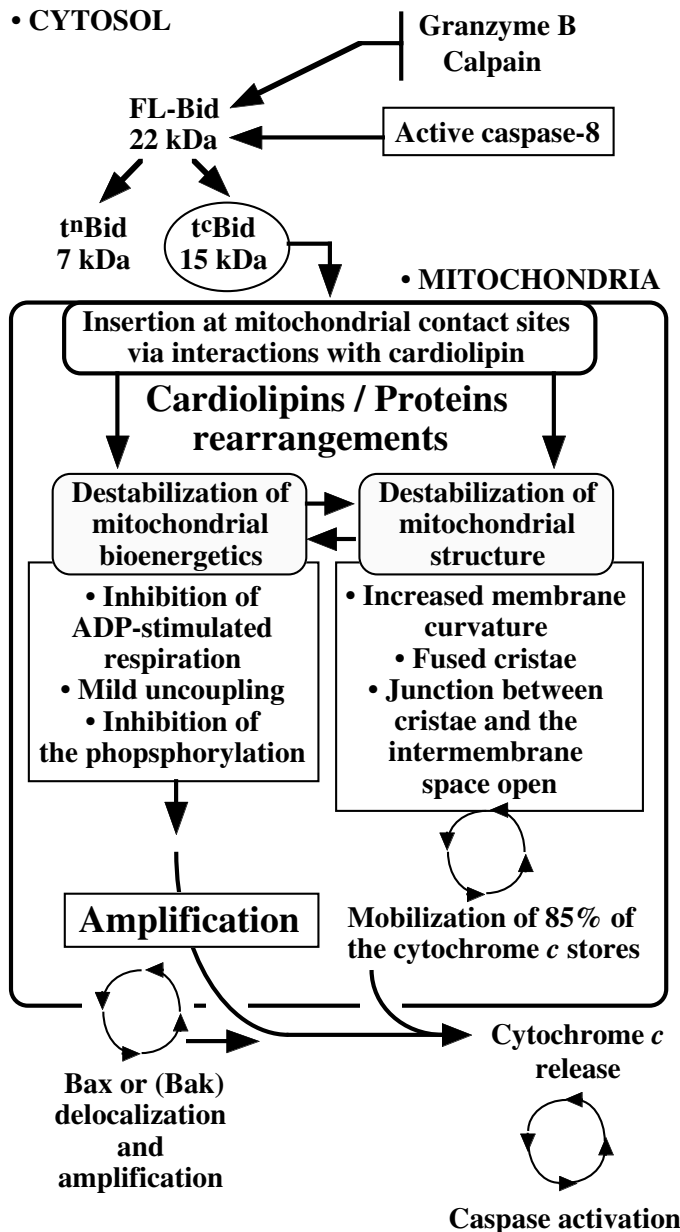

Figure 7 Schematic representation of the effects of tBid on mitochondria and subsequent consequences

results are in direct line with the observation that tBid induces Bax and Bak oligomerization at the mitochondrial membrane. $^{28}$

Based on these observations, we propose a two-step model (Figure 7) in which tBid plays a primary role in destabilizing mitochondrial membrane structure and function. This function of tBid relates to its ability to bind cardiolipin, and to enhance the delocalization of Bax (or Bak) from the cytoplasm to the mitochondrial membrane, their oligomerization, and consequently contributes to the amplification of the mitochondrial damage, which culminates with cytochrome $c$ release.

\section{Materials and Methods}

\section{Materials}

All chemicals and supplies were obtained from Sigma (St. Louis, MO, USA) unless otherwise stated. Full-length His-tagged mouse Bid, wild-type and mutants, were purified as described by Desagher et al. ${ }^{29}$ We used tBid stock solutions $(1.9 \mathrm{mg} / \mathrm{ml})$ diluted in $\mathrm{nM}$ dose in the respiratory buffer. The buffer alone has no effect on mitochondrial parameters.

Peptides were synthesized on a Rainin Symphony synthesizer using a standard SPPS (solid phase peptide synthesis) method (Novabiochem). ${ }^{15}$ Bid BH3 peptide was synthesized with the following sequence 
RNIARHLAQVGDSMDR and was used at nontoxic concentrations (less than $5 \mu \mathrm{M}$ ). The toxicity of the Bid-BH3 peptide has been tested on purified mitochondria bioenergetics with the same protocol as for tBid (see below).

\section{Animals \\ Studies were performed on 6-12-week-old mice (control [C57/B/6]) and age- and sex-matched congenic mice expressing a $\mathrm{Bcl}-2^{30}$ or $\mathrm{Bcl}-\mathrm{XL}$ transgene ${ }^{31}$ under the L-type pyruvate kinase gene promoter and on $\mathrm{Bax}^{-1-}$ and $\mathrm{Bak}^{-1-}$ mice (kindly provided by $\mathrm{CB}$ Thompson and $\mathrm{S}$ Korsmeyer, USA). \\ Purification of mouse liver mitochondria and mitoplasts}

Mice were killed by decapitation and their livers removed and placed in cold medium $\mathrm{H}$ (pH 7.2) containing $0.3 \mathrm{M}$ sucrose, $5 \mathrm{mM}$ TES, $0.2 \mathrm{mM}$ EGTA, and $0.1 \% \mathrm{BSA}(\mathrm{w} / \mathrm{v})$. Mitochondria were isolated by classical differential centrifugation to obtain a crude mitochondrial preparation. ${ }^{32}$ The crude mitochondria were layered on a Percoll gradient (10 min at $8500 \times \mathrm{g}$ ) consisting of three layers $(18,30$ and $70 \%$ [v/v]) of Percoll in medium $\mathrm{H}$. Purified mitochondria were collected from the $30 / 70 \%$ interface and washed with medium $\mathrm{H}$. We used the same procedure for mitochondria from $\mathrm{Bcl}-2^{30}$ and $\mathrm{Bcl}-\mathrm{XL}^{31}$ transgenic mice, and for bax ${ }^{-1-}$ and bak $^{-1-}$ mice.

Mitoplasts were generated by incubating fresh mitochondria in hypotonic buffer (ratio 1:10 mitochondria/hypotonic buffer, $v / v$ ) in $20 \mathrm{mM}$ HEPES, $1 \mathrm{mg} / \mathrm{ml} \mathrm{BSA}$ ( $\mathrm{pH} \mathrm{7.4)}$ for $20 \mathrm{~min}$ at $4^{\circ} \mathrm{C}$. The resulting mitoplasts were separated by centrifugation $\left(6800 \times \mathrm{g}, 10 \mathrm{~min}, 4^{\circ} \mathrm{C}\right)$ and layered on top of a Percoll gradient $(10 \mathrm{~min}$ at $8500 \times \mathrm{g})$ consisting of three layers $(18,30$ and $70 \%[\mathrm{v} / \mathrm{v}])$ of Percoll. The functional mitoplasts were recovered at the $30: 70 \%$ interface.

\section{Oxygen uptake, membrane potential, rate of phosphorylation and large amplitude swelling}

Purified mitochondria were resuspended in respiratory medium (R) consisting of $100 \mathrm{mM} \mathrm{KCl}, 40 \mathrm{mM}$ sucrose, $5 \mathrm{mM} \mathrm{MgCl} 2,10 \mathrm{mM}$ TES, $10 \mathrm{mM} \mathrm{KH}_{2} \mathrm{PO}_{4}(\mathrm{pH} 7.2), 1 \mathrm{mM}$ EGTA and 0.1\% BSA. The mitochondrial protein concentration used for measurement was $0.333 \mathrm{mg} / \mathrm{ml}$ (in a $3 \mathrm{ml}$ cuvette). The mitochondrial respiration rate $\left(V_{o x}\right)$ and membrane potential $\left(\Delta \Psi_{\mathrm{m}}\right)$ were monitored by the simultaneous use of a Clark-type electrode, a tetraphenylphosphonium cation-sensitive electrode (TPP $\left.{ }^{+}\right)$and a $\mathrm{pH}-$ electrode, at $25^{\circ} \mathrm{C}$ in medium R. Membrane potential was calculated according to Kamo et al. ${ }^{33}$ and the TPP ${ }^{+}$binding was corrected according to Rottenberg. ${ }^{34}$ The phosphorylation rate was estimated from the $\mathrm{H}^{+}$ influx, estimated by $\mathrm{pH}$ changes, and each curve was calibrated with increasing amounts of $0.1 \mathrm{~N} \mathrm{HCl}^{35}$ The swelling of mitochondria was estimated from the decrease in absorbance measured at $520 \mathrm{~nm}$ in a Cary 50 spectrophotometer (Varian SA, Australia) in hypotonic swelling medium

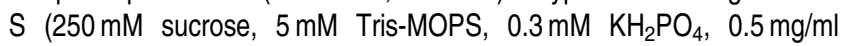
oligomycin, $5 \mathrm{mM}$ succinate and $2 \mu \mathrm{M}$ rotenone at $\mathrm{pH} 7.2$ ). Inorganic phosphate $(250 \mathrm{mM})$ was added to ensure optimal succinate transport and subsequent succinate dehydrogenase activity. Trace amounts of EGTA $(10 \mu \mathrm{M})$ ensured good experimental reproducibility without affecting the pore opening. Mitochondria from control or transgenic mice were incubated in medium $\mathrm{S}(0.33 \mathrm{mg} / \mathrm{ml})$, treated with $5 \mu \mathrm{M}$ atractyloside (plus low concentrations of $\mathrm{Ca}^{2+}(100 \mu \mathrm{M})$ for preconditioning), or terbutyl-hydroperoxide $(50 \mu \mathrm{M})$, or calcium $300 \mu \mathrm{M}$.

\section{In vitro assay of cytochrome $c$ release and calcein release}

Purified mouse liver mitochondria were resuspended in medium $\mathrm{R}(\mathrm{pH}$ 7.2). An amount of $5 \mu \mathrm{l}$ of isolated mitochondria (stock concentration $25 \mathrm{mg} / \mathrm{ml}$ ) was mixed by gentle stirring with the indicated amount of proteins or compounds plus $4 \mu$ l of protease inhibitors cocktail (Sigma) in a final volume of $50 \mu \mathrm{l}$ medium $S$ for $30 \mathrm{~min}$ at room temperature. Mitochondria were then collected by centrifugation at $12000 \times g$ for 5 min at $4{ }^{\circ} \mathrm{C}$ and the supernatants were analyzed by $15 \%$ SDS-PAGE and using a mouse monoclonal anti-cytochrome $c$ antibody (Pharmingen, clone 7H8.2C12).

For calcein release, mitochondria suspended in respiration medium $(R)$ without BSA were loaded with $10 \mathrm{nM}$ calcein-AM (Molecular Probes) for $20 \mathrm{~min}$ at room temperature in the dark. Following two washes, $0.5 \mathrm{mg} / \mathrm{ml}$ calcein-loaded mitochondria were incubated in a calcein measurement medium (125 mM KCl, $10 \mathrm{mM}$ tris-MOPS (pH 7.4), $1 \mathrm{mM} \mathrm{Pi}, 5 \mathrm{mM}$ succinate, $10 \mu \mathrm{M}$ EGTA-Tris ( $\mathrm{pH} 7.4$ ), a concentration which does not block the PTP opening but ensures reproductivity to the measurements) and treated as described in the Figure 5. After the indicated time, mitochondria were spun down. Calcein was measured in the spin down supernatant in an LS-50B spectrofluorometer (Perkin-Elmer) with excitation and emission wavelengths set at $488 \pm 2.5$ and $542 \pm 2.5 \mathrm{~nm}$, respectively. Calcein release is reported as the percentage of the calcein measured in the supernatant over the total (pellet + supernatant).

\section{ATPIADP translocase activity in purified mitochondria}

Percoll-purified liver mitochondria (from female, 6-12-week-old C57/BI6 mice and age- and sex-matched congenic mice) were suspended $(10 \mathrm{mg}$ protein per $500 \mu \mathrm{l}$ ) in $0.6 \mathrm{M}$ mannitol, $0.2 \% \mathrm{BSA}, 10 \mathrm{mM} \mathrm{MOPS}$, and $0.1 \mathrm{mM}$ EDTA (pH 6.8). For kinetic analyses of ADP/ATP exchange, we modified the method developed by Pfaff et al. ${ }^{36}$ Purified mitochondria were incubated with $15 \mu \mathrm{l}\left[2,8^{3} \mathrm{H}\right]$ ATP $(40 \mathrm{Ci} / \mathrm{mmol})$ at $4^{\circ} \mathrm{C}$ after a preincubation of $45 \mathrm{~min}$ in the presence or absence of $\mathrm{tBid}$. They were then washed twice to eliminate free $\left[2,8-{ }^{3} \mathrm{H}\right] \mathrm{ATP}$. Exchange was initiated by adding cold $\operatorname{ADP}(400 \mu \mathrm{M})$ and stopped after $10 \mathrm{~s}$ by adding $100 \mu \mathrm{M}$ atractyloside and centrifugation $\left(6800 \times \mathrm{g}, 10 \mathrm{~min}, 4^{\circ} \mathrm{C}\right) .^{37}$

\section{Recombinant proteins and coimmunoprecipitation}

IVT proteins were transcribed in vitro and translated as described by Wei et $a l^{38}$ whereas recombinant tBid or tBidlllm were either purified as described by Wei et al..$^{38}$ or as described by Desagher et al. ${ }^{29}$

${ }^{35}$ S-labelled IVT proteins were incubated with Percoll-purified mouse liver mitochondria for various periods of time $(10-30 \mathrm{~min})$ at $30^{\circ} \mathrm{C}$. The mitochondria were then solubilized and incubated with anti-Bak antibody for $1 \mathrm{~h}$ at $4^{\circ} \mathrm{C}$ as described by Wei et al. ${ }^{38}$ The beads were then analyzed by fluorography for bound proteins.

\section{Yeast cell mitochondria}

Wild-type yeast strain and the cardiolipin synthase-deficient strain WKEN011 $\mathrm{A}^{39}$ were grown aerobically at $28^{\circ} \mathrm{C}$ in complete medium $(1 \%$ yeast extract, $0.12 \%$ ammonium sulfate, $0.1 \%$ potassium phosphate, $2 \%$ DL-lactate, pH 5.2) until the mid-exponential growth phase. Cells were harvested and mitochondria were isolated as described previously. ${ }^{40}$ Mitochondria were suspended at $0.17 \mathrm{mg} / \mathrm{ml}$ in $10 \mathrm{mM}$ Tris-maleate buffer (pH 6.8) containing $0.6 \mathrm{M}$ mannitol and $2 \mathrm{mM}$ EGTA. Respiration rates 
were measured at $28^{\circ} \mathrm{C}$ in the presence of $5 \mathrm{mM}$ potassium phosphate, $1 \mathrm{mM} \mathrm{NADH}$ and $50 \mu \mathrm{M} \mathrm{ADP}$ (state 3). Mitochondria were preincubated with $\mathrm{tBid}$ for the indicated time periods. ATP synthesis was measured in the presence of $1 \mathrm{mM} \mathrm{ADP}$ with $1 \mathrm{mM} \mathrm{NADH}$ as substrate, and in the presence of AP5A $13 \mathrm{mg} / \mathrm{ml}$, an inhibitor of the adenylate kinase. Samples $(150 \mu \mathrm{l})$ were removed at $0,10,20$ and $30 \mathrm{~s}$ after adding ADP. Proteins were precipitated by adding $50 \mu \mathrm{l} \%$ perchloric acid in $50 \mathrm{mM}$ EDTA and the samples cleared by centrifugation. Aliquots $(150 \mu \mathrm{l})$ of supernatant were neutralized by adding $24 \mu \mathrm{l} 0.3 \mathrm{M} \mathrm{MOPS} / 2 \mathrm{~N} \mathrm{KOH}$, and ATP was measured with a luciferin/luciferase kit (Bio-orbit) in an LKB bioluminometer. Rates of ATP synthesis were calculated from linear regression plots of ATP produced versus time.

\section{Biophysical measurements on lipid monolayers}

All monolayer experiments were carried out in Teflon dishes at $22^{\circ} \mathrm{C}$. Monolayers of pure or mixed phospholipids were spread on a subphase buffer ( $5 \mathrm{mM}$ Tris- $\mathrm{HCl}, \mathrm{pH} 7.5$ and $150 \mathrm{mM} \mathrm{NaCl}$ ) to give an initial surface pressure of $20 \mathrm{mN} / \mathrm{m}$. tBid was added to the stirred subphase. The pressure changes were monitored until the increase in surface pressure was maximal.

Epifluorescence observations were made with an Olympus-BX30 microscope. The fluorescent probe 1-palmitoyl-2\{6[(7-nitro-2-1,3-benzoxadizol-4-yl)amino]dodecanoyl\} phosphatidylglycerol (NBD-PG, purchased from Avanti Polar Lipids Inc., USA) was excited at $470 \mathrm{~nm}$ using a mercury lamp and its emission recorded at $530 \mathrm{~nm}$. Mixtures were prepared from a chloroform solution of DPPC containing the desired proportions of cardiolipin and $0.5 \mathrm{~mol} \% \mathrm{NBD}-\mathrm{PG}$. This hydrophilic probe is excluded from densely packed areas of lipid, providing contrast between lipid phases.

\section{Microspectrofluorometric analysis}

Microspectrofluorometric analysis was performed under epi-illumination conditions by means of Zeiss UMSP 80 confocal microscope equipped with an UV-visible argon laser and an optical multichannel analyzer (OMA III with an IRY 1024/6B from Princeton Applied Research). The acquisition system and data treatment were carried out with a Prism system (Jobin \& Yvon). The excitation was set at $488 \mathrm{~nm}$ and the spectra were recorded in the $540-750 \mathrm{~nm}$ range. The size of the area where the spectra are recorded is $0.8 \mu \mathrm{m}$. The spectra of EYFP (empty vector from BD Bioscience, USA, cytoplasmic) and of the mitochondrially localized CMXRos (Chloromethyl-X-Rosamine, Molecular Probes, USA) are presented in Figure $3 \mathrm{~b}$ as references. CMXRos was added to the cells at a final concentration of $20 \mathrm{nM}$ (preincubation time $15 \mathrm{~min}$ at room temperature).

\section{Acknowledgements}

We thank E Gottlieb (Beatson Cancer Institute, Glasgow, UK) and Professor J Hanoune (Institut Cochin, Paris, France) for helpful discussions and corrections of the manuscript, and also $E$ Hendrickson for helpful discussions at the Keystone meeting 'Molecular Mechanisms of Apoptosis' held in Banff (Alberta, Canada in February 2003). We also thank Professor $\mathrm{P}$ Canioni, Director of the laboratory 'Résonance Magnétique des Systèmes Biologiques' (CNRS UMR 5536, Université Bordeaux 2, France) for giving access to his laboratory during this work. This work was supported by the ARC (Association de Recherche sur le Cancer), Grant Number 4493 (to PXP).

\section{References}

1. Vayssière J-L, Petit PX, Risler $Y$ and Mignotte B (1994) Commitment to apoptosis is associated with changes in mitochondrial biogenesis and activity in cell lines conditionally immortalized with simian virus 40 . Proc. Natl. Acad. Sci. USA 91: 11752-11756

2. Petit PX, Lecoeur H, Zorn E, Dauguet C, Mignotte B and Gougeon ML (1995) Alterations of mitochondrial structure and function are early events of dexamethasone-induced thymocyte apoptosis. J. Cell Biol. 130: 157-167

3. Kroemer G, Petit PX, Zamzami N, Vayssière J-L and Mignotte B (1995) The biochemistry of apoptosis. FASEB J. 9: 1277-1287

4. Wang $X$ (2001) The expanding role of mitochondria in apoptosis. Genes Dev. 15: 2922-2933

5. Newmeyer DD, Ferguson-Miller S, Kuwana T, Mackey MR, Perkins G, Ellisman MH, Latterich M, Schneiter R and Green DR (2003) Mitochondria: releasing power for life and unleashing the machineries of death Bid, Bax, and lipids cooperate to form supramolecular openings in the outer mitochondrial membrane. Cell 112: 481-490

6. Gross A, McDonnell JM and Korsmeyer SJ (1999) Bcl-2 familly members and mitochondria in apoptosis. Genes Dev. 1999: 1899-1911

7. Martinou JC and Green DR (2001) Breaking the mitochondrial barrier. Nat. Rev. Mol. Cell Biol. 2: 63-67

8. Zamzami N and Kroemer G (2001) The mitochondrion in apoptosis: how Pandora's box opens. Nat. Rev. Mol. Cell Biol. 2: 67-71

9. van Loo G, Saelens X, van Gurp M, MacFarlane M, Martin SJ and Vandenabeele $P(2002)$ The role of mitochondrial factors in apoptosis: a Russian roulette with more than one bullet. Cell Death Differ. 9: 1031-1042

10. Ricci JE, Gottlieb RA and Green DR (2003) Caspase-mediated loss of mitochondrial function and generation of reactive oxygen species during apoptosis. J. Cell Biol. 160: 65-75

11. Gottlieb E, Armour SM, Harris MH, Thompson CB, Vander Heiden MG, Oren M, Eizenberg O, Faber-Elman A, Rotter V, Schwartz M, Lindner S, Haffner R, von Ruden T and Wagner EF (2003) Mitochondrial membrane potential regulates matrix configuration and cytochrome $c$ release during apoptosis. Cell Death Differ. 10: 709-717

12. Manfredi G, Kwong JQ, Oca-Cossio JA, Aurelio MD, Gajewsky CD, Beal FM, Moraes CT, Zimmermann VS, Bondanza A, Rovere-Querini P, Colombo B, Sacchi A, Fascio U, Corti A, Manfredi AA, Torre D, Tambini R, Manfredi M, Mangani V, Livi P, Maldifassi V, Campi P, Speranza F, Manfredi JJ, Gaipl US, Beyer TD, Baumann I, Voll RE, Stach CM, Heyder P, Kalden JR, Manfredi A and Herrmann M (2001) Bcl-2 suppresses oxidative phosphorylation defects caused by mitochondrial DNA mutations. Sci. World J. 1: 39

13. Adams JM and Cory S (2001) Life-or-death decisions by the Bcl-2 protein family. Trends Biochem. Sci. 26: 61-66

14. Li H, Zhu H, Xu CJ and Yuan J (1998) Cleavage of BID by caspase 8 mediates the mitochondrial damage in the Fas pathway of apoptosis. Cell 94: 491-501

15. Luo X, Budihardjo I, Zou H, Slaughter C and Wang X (1998) Bid, a bcl-2 interacting protein, mediates cytochrome $c$ release from mitochondria in response to activation of cell surface receptors. Cell 94: 481-490

16. Korsmeyer SJ, Wei MC, Saito M, Weiler S, Oh KJ and Schlesinger PH (2000) Pro-apoptotic cascade activates BID, which oligomerizes BAK or BAX into pores that result in the release of cytochrome $c$. Cell Death Differ. 7: 1166-1173

17. Lutter M, Fang M, Luo X, Nishijima M, Xie X and Wang X (2000) Cardiolipin provides specificity for targeting of tBid to mitochondria. Nat. Cell Biol. 2: 754761

18. Lutter M, Perkins GA and Wang X (2001) The pro-apoptotic Bcl-2 family member tBid localizes to mitochondrial contact sites. BMC Cell Biol. 2: 22

19. Scorrano L, Ashiya M, Buttle K, Weiler S, Oakes SA, Mannella CA and Korsmeyer SJ (2002) A distinct pathway remodels mitochondrial cristae and mobilizes cytochrome $c$ during apoptosis. Dev. Cell. 2: 55-67

20. Epand RF, Martinou JC, Fornallaz-Mulhauser M, Hughes DW and Epand RM (2002) The apoptotic protein tBid promotes leakage by altering membrane curvature. J. Biol. Chem. 277: 32632-32639, Epub 2002 Jun 24

21. Cullis PR, Verkleij AJ and Ververgaert PH (1978) Polymorphic phase behaviour of cardiolipin as detected by 31P NMR and freeze-fracture techniques. Effects of calcium, dibucaine and chlorpromazine. Biochim. Biophys. Acta 513: 11-20

22. Ortiz A, Killian JA, Verkleij AJ and Wilschut J (1999) Membrane fusion and the lamellar-to-inverted-hexagonal phase transition in cardiolipin vesicle systems induced by divalent cations. Biophys. J. 77: 2003-2014 
23. de Kroon Al, Dolis D, Mayer A, Lill R and de Kruiff B (1997) Phospholipid composition of highly purified mitochondrial outer membranes of rat liver and Neurospora crassa. Is cardiolipin present in the mitochondrial outer membrane? Biochim. Biophys. Acta 1325: 108-116

24. Hovius R, Lambrechts H, Nicolay K and de Kruijff B (1990) Improved methods to isolate and subfractionate rat liver mitochondria. Lipid composition of the inner and outer membrane. Biochim. Biophys. Acta 1021: 217-226

25. Hoffmann B, Stockl A, Schlame M, Beyer K and Klingenberg M (1994 The reconstituted ADP/ATP carriers activity has an absolute requirement for cardiolipin as shown in cysteine mutants. J. Biol. Chem. 269: 1940-1944

26. Beyer K and Klingenberg M (1985) ADP/ATP carrier protein from beef heart mitochondria has high amounts of tightly bound cardiolipin, as revealed by $31 \mathrm{P}$ nuclear magnetic resonance. Biochemistry 24: 3821-3826

27. Van der Heiden MG, Chandel NS, Williamson EK, Schumacher PJ and Thompson CB (1997) Bcl-XL regulates the membrane potential and volume homeostasis of mitochondria. Cell 91: 627-637

28. Roucou X, Rostovtseva T, Montessuit S, Martinou JC and Antonsson B (2002) Bid induces cytochrome $c$-impermeable Bax channels in liposomes. Biochem. J. 363: $547-552$

29. Desagher S, Osen-Sand A, Nichols A, Eskes R, Montessuit S, Lauper S, Maundrell K, Antonsson B and Martinou JC (1999 Bid-induced conformational change of Bax is responsible for mitochondrial cytochrome $c$ release during apoptosis. J. Cell Biol. 144: 891-901

30. Lacronique V, Mignon A, Fabre M, Viollet B, Rouquet N, Molina T, Porteu A, Henrion A, Bouscary D, Varlet P, Joulin V and Kahn A (1996) Bcl-2 protects from lethal hepatic apoptosis induced by an anti-Fas antibody in mice. Nat. Med. 2: 80-86

31. de la Coste A, Fabre M, McDonnel N, Porteu A, Gilgenkrantz H, Perret C, Kahn A and Mignon A (1998) Bcl-XL and Bcl-2 differentially block fas/CD95- and TNF $\alpha$-induced apoptotic liver injury in transgenic mice. Am. J. Physiol. 59: 5017-5022

32. Petit PX, O'Connor JE, Grunwald D and Brown SC (1990) Analysis of the membrane potential of rat- and mouse-liver mitochondria by flow cytometry and possible applications. Eur. J. Biochem. 220: 389-397

33. Kamo N, Muratsugu M, Hongoh M and Kobatake Y (1979) Membrane potential of mitochondria measured with an electrode to tetraphenylphosphonium and relationship between proton electrochemical gradient and phosphorylation potential in steady state. J. Membr. Biol. 49: 105-121

34. Rottenberg $\mathrm{H}$ (1984) Membrane potential and surface potential in mitochondria: uptake and binding of lipophilic cations. J. Membr. Biol. 81: 127-138

35. Leducq N, Delmas-Beauvieux MC, Bourdel-Marchasson I, Dufour S, Gallis JL, Canioni P and Diolez P (1998) Mitochondrial permeability transition during hypothermic to normothermic reperfusion in rat liver demonstrated by the protective effect of cyclosporin A. Biochem. J. 336: 501-506

36. Pfaff $E$, Heldt HW and Klingenberg M (1969) Adenine nucleotide translocation of mitochondria. Kinetics of the adenine nucleotide exchange. Eur. J. Biochem. 10: 484-493

37. Belzacq A-S, Viera HLA, Verrier F, Vandecasteele G, Larquet E, Cohen I, Prévost M-C, Pariselli F, Petit PX, Kahn A, Rizzuto R, Brenner C and Kroemer $\mathrm{G}$ (2003) BCL-2 and BAX modulate adenine nucleotide translocase activity. Cancer Res. 63: 541-546

38. Wei MC, Lindsten T, Mootha VK, Weiler S, Gross A, Ashiya M, Thompson CB and Korsmeyer SJ (2000) tBID, a membrane-targeted death ligand, oligomerizes BAK to release cytochrome c. Genes Dev. 14: 2060-2071

39. Shimizu S and Tsujimoto Y (2000) Proapoptotic BH3-only Bcl-2 family members induce cytochrome $c$ release, but not mitochondrial membrane potential loss, and do not directly modulate voltage-dependent anion channel activity. Proc. Natl. Acad. Sci. USA 97: 577-582

40. Guerin B, Labbe P and Somlo M (1979) Preparation of yeast mitochondria (Saccharomyces cerevisiae) with good P/O and respiratory control ratios. Methods Enzymol. 55: 149-159

41. Yang JC, Kahn A and Cortopassi G (2000) Bcl-2 does not inhibit the permeability transition pore in mouse liver mitochondria. Toxicology 151 65-72

42. Ardail D, Privat JP, Egret-Charlier M, Levrat C, Lerme F and Louisot $P(1990)$ Mitochondrial contact sites. Lipid composition and dynamics. J. Biol. Chem. 265: 18797-18802

43. Murphy AN, Bredesen DE, Cortopassi G, Wang E and Fiskum G (1996) Bcl-2 potentiates the maximal calcium uptake capacity of neural cell mitochondria. Proc. Natl. Acad. Sci. USA 93: 9893-9898

44. Kluck RM, Esposti MD, Perkins G, Renken C, Kuwana T, Bossy-Wetzel E, Goldberg M, Allen T, Barber MJ, Green DR and Newmeyer DD (1999) The proapoptotic proteins, Bid and Bax, cause a limited permeabilization of the mitochondrial outer membrane that is enhanced by cytosol. J. Cell Biol. 147: 809-822

45. Petronilli V, Miotto G, Canton M, Brini M, Colonna R, Bernardi P and Di Lisa F (1999) Transient and long-lasting openings of the mitochondrial permeability transition pore can be monitored directly in intact cells by changes in mitochondrial calcein fluorescence. Biophys. J. 76: 725-734

46. Bernardi P, Scorrano L, Colonna R, Petronilli V and Di Lisa F (1999) Mitochondria and cell death. Mechanistic aspects and methodological issues. Eur. J. Biochem. 264: 687-701

47. Huser J, Rechenmacher CE and Blatter LA (1998) Imaging the permeability pore transition in single mitochondria. Biophys. J. 74: 2129-2137 